University of St.Gallen

\title{
«THE ROLE OF THE END TIME IN EXPERIMENTAL ASSET MARKETS»
}

ANITA KopÁnYi-PeUKer

MATTHIAS WEBER

WORKING PAPERS ON FINANCE No. 2021/12

SWISS INSTITUTE OF BANKING AND FINANCE (S/BF - HSG)

JULY 21, 2021 


\title{
The Role of the End Time in Experimental Asset Markets*
}

\author{
Anita Kopányi-Peuker ${ }^{\dagger} \quad$ Matthias Weber ${ }^{\dagger}$
}

July 19, 2021

\begin{abstract}
By now there are hundreds of scientific articles on experimental asset markets. Almost all of these experiments use a short and definite horizon. This may be one of the starkest differences to financial asset markets outside the laboratory, which usually have indefinite and comparatively long horizons. We analyze the role of the end time in an asset market experiment in which we vary the length of the horizon and whether the end time is definite or indefinite. We find recurring bubbles and similar price dynamics in all treatments (with moderately lower prices in the treatments with a long horizon).
\end{abstract}

JEL classification: C92, G40, G41, D90.

Keywords: Experimental finance; asset market experiments; time horizon; indefinite end time; bubbles.

"For comments and suggestions, we would like to thank Olimpia Carradori, Christos Ioannou, Tomasz Makarewicz, participants of the Economic Science Association Global Online Conference, the Third Behavioral Macroeconomics Workshop (Bamberg), the Experimental Finance Conference 2021 (Innsbruck), the Third Virtual Experimental Finance Workshop, and seminar participants at Radboud University Nijmegen and the University of Amsterdam. Financial support from University of St. Gallen GFF Project Funding is gratefully acknowledged.

†Radboud University, Nijmegen. Email: anita.kopanyi-peuker@ru.nl.

School of Finance, University of St. Gallen. Email: matthias.weber@unisg.ch. 


\section{Introduction}

Experiments have become an important tool when analyzing human interaction in financial markets. ${ }^{1}$ The reason for this is the control that experiments offer. The usual problems that exist with observational data (such as omitted variable bias or reverse causality) do not exist in the laboratory: the randomization to treatments in general allows to make causal claims about treatment effects. In addition, it is possible to observe fundamental values, which is in general not possible outside the laboratory. While it may seem obvious to some that price bubbles can exist in actual financial markets (thinking, for instance, of the Dutch Tulip Bubble, the South Sea Bubble, or the Dotcom Bubble), others may deny the existence of bubbles and the possibility to identify a bubble while prices are rising or at their peak (rather than just classifying bubbles ex post). As fundamentals are unobservable, prices might be justified by expectations at any point in time, and the fact that prices decrease at some point do not proof that these expectations were incorrect ex ante. Indeed, Nobel Memorial Prize in Economic Sciences laureate Eugene Fama already argued the latter viewpoint: "I don't even know what a bubble means. These words have become popular. I don't think they have any meaning." ${ }^{2}$ In the laboratory, fundamental values can be observed and substantiated claims about price accuracy can be made in a straightforward manner.

Most of the experimental literature relies on definite horizons and a relatively low number of periods of about ten to twenty. This could be considered one of the greatest differences to actual financial markets. While a financial asset in the real world may not exist forever,

\footnotetext{
${ }^{1}$ There are by now hundreds of papers on experimental asset markets. Reviews of the literature can, for instance, be found in Bossaerts (2009), Palan (2013), or Powell and Shestakova (2016). Recent contributions include Bossaerts et al. (2010), Palan (2010), Cheung and Palan (2012), Kirchler et al. (2012), Sutter et al. (2012), Huber and Kirchler (2012), Cheung et al. (2014), Füllbrunn et al. (2014), Noussair et al. (2016), Bao et al. (2017), Holt et al. (2017), Bosch-Rosa et al. (2018), Weber et al. (2018), Charness and Neugebauer (2019), Ahrens et al. (2020), Tucker and Xu (2020), Weitzel et al. (2020), Hommes et al. (2021), and Lambrecht et al. (2021).

${ }^{2}$ This quote is from an interview in 2010 with John Cassidy for The New Yorker: https://www.newyorker.com/news/john-cassidy/interview-with-eugene-fama.
} 
such assets usually last for a long time and it is uncertain when they cease to exist (they thus have an indefinite ending). Whether the end time of an asset is definite or indefinite could have considerable implications for how people price assets. It is, for instance, straightforward to conduct backward induction when the end time is definite, especially with a short planning horizon. In the world outside the laboratory, this might be a reason why we usually think of equity markets when talking about bubbles and not about bond markets - bonds generally have a fixed end time (although risky bonds might default before this fixed end time). In this paper, we analyze which role the definiteness and the length of the time horizon play for the pricing of experimental assets.

Compared to the literature with definite horizons, there are only very few papers with indefinite horizons. As the experimental asset market literature is by now very large and diverse, it is not surprising that there are nevertheless already some papers that make use of an indefinite end time in the laboratory (e.g., Hens and Steude, 2009; Asparouhova et al., 2016; Fenig et al., 2018; Crockett et al., 2019; Weber et al., 2019; Duffy et al., 2020). However, this literature in general does not compare markets with an indefinite end to the same markets with a definite end (the focus lies often on comparing different treatments with indefinite ends). Concerning the length of the horizon, there are some studies with more periods than the usual ten to twenty (e.g., Lahav, 2011; Hoshihata et al., 2017) but surprisingly basically none that vary the length of the horizon in a controlled way (an exception is Razen et al., 2017, who have markets with eight and 14 periods). This also means that, to the best of our knowledge, there is no study varying the horizon length with indefinite end times (or with repeated markets to allow the analysis of learning across repetitions).

To preview our results, we find no sizable or significant effect of whether the end is definite or indefinite. This holds for the extent of overpricing, as well as for the degree of pricing improvements across rounds and for the speeding up of bubbles (that is, bubbles appearing earlier in a round in later rounds of the experiment). The length of the horizon 
has an effect on overpricing: prices are on average lower in the treatments with a long horizon. The length of the horizon has no significant or sizable effect on increasing of pricing accuracy across rounds or on the speeding up of bubbles. Slight pricing improvements and speeding up of bubbles are observed across the different rounds.

We consider our results as confirmation for the findings from the literature on asset market experiments. Given that we find no qualitative differences in pricing behavior across the different treatments (and only level differences in market prices between markets with short and long horizons), it is unlikely that the results obtained in the literature, which are usually treatment comparisons, are artifacts of definite and relatively short time horizons.

This paper is organized as follows. We present the experimental design in Section 2. Section 3 contains the results. Section 4 concludes.

\section{Experimental Design}

\subsection{The call market}

Our experiment relies on a call market setting. Six subjects form one market (or group), and they can trade assets with each other. Each session consists of three independent market rounds, where each round consists of several trading periods (when a round ends is a treatment variable and discussed in Section 2.2). Each subject starts each round with the same initial endowment of three assets and 5,500 points in their cash account. In each period, subjects have the opportunity to trade assets by submitting marginal bids and asks simultaneously. Afterwards, the computer calculates the market price by constructing the demand and supply functions from the submitted bids and asks. The market price is determined by the intersection of these two functions. If there are no bids, no asks, or if the highest bid is lower than the lowest ask, there is no trade in the given period. Furthermore, if there is excess demand or supply for the determined market price, it is 
randomly determined which bids or asks are executed of those bids or asks exactly at the market price. If there is an interval of possible market prices (because of a vertical overlap of market demand and supply schedules), the realized market price is exactly the midpoint of this interval. Subjects are allowed to submit multiple bids and asks at the same time, but they face the following constraints while trading:

1. Short-selling is not allowed: subjects cannot offer more assets to sell than they own, and similarly they cannot try to buy more assets than there are available on the market (18 minus their own asset holdings).

2. Borrowing money is not allowed: subjects cannot submit bids that they cannot pay for with their current cash holdings.

3. No self-trade: the highest bid submitted by subjects cannot be higher than their own lowest ask, that is, they are not allowed to trade with themselves.

If any of these constraints is violated, the software displays an error message, and subjects have to reconsider their bids and asks.

After each trading period, thus after the market price is computed and trade is executed, dividend and interest earnings are paid out. Each asset pays a random dividend in each period: the dividend is either 0 or 10 points, both with equal probability, and the dividend is the same for all assets in a given period. The interest rate on cash is $4 \%$, and applies to all cash subjects hold at the end of the trading period. Both interest and dividend earnings are paid to a separate savings account. This savings account also pays interest, but subjects cannot use money in this account to buy assets. This leads to a cash-to-asset ratio that is constant across all periods.

When a round ends, subjects receive 125 points for each asset that they hold at this time. These 125 points correspond to the constant fundamental value of the asset (which can be calculated as the expected dividend divided by the interest rate). Pricing the asset at the fundamental value gives a cash-to-asset ratio of $5,500 /(3 * 125) \approx 14.67$, which is relatively 
high compared to previous studies. We have chosen this high cash-to-asset ratio, because we believe that it is more representative of actual asset markets (with a lot of cash/wealth available in comparison to the value of any single asset). Furthermore, we are interested in how the different end times affect bubble formation and mispricing and therefore there needs to be space for bubbles to arise.

In each period subjects have a limited amount of time to make their decisions. They have two minutes in the first ten periods of the first round and one minute in all other periods. If subjects do not make a decision within this time, the computer automatically proceeds to the next period not submitting any bids or asks for that subject in the given period. Subjects can also decide not to trade by submitting an empty schedule. Throughout the experiment subjects can see the history of the current round: they receive graphical information about the realized market price and they can see their own trades and cash and asset balances in a table. For an example of a subject's decision screen, see Online Appendix A.

\subsection{Treatments}

The experimental design is a $2 \times 2$ factorial design. In one treatment dimension, we vary the length of a round, with a short horizon of about 15 periods and a long horizon of about 30 periods. In the second treatment dimension, we vary whether the rounds have a definite or indefinite ending. This leads to four treatments: short-definite, short-indefinite, longdefinite, and long-indefinite. ${ }^{3}$ In all treatments, markets are as described above, the only difference arises in the number of periods per market round (and in whether these numbers are known beforehand). In the definite treatments all rounds have 15 (short-definite) or 30 (long-definite) periods per round. In the indefinite treatments, we implement a minimum number of periods for each round (13 in short-indefinite and 28 in long-indefinite),

\footnotetext{
${ }^{3}$ Treatment long-indefinite is similar to the full information treatment of the call market in Kopányi-Peuker and Weber (2021) but not identical. The differences are (except for the exact number of periods) that markets are terminated by discretion rather than relying on a continuation probability in Kopányi-Peuker and Weber (2021) and that there is an upper bound of 1500 on bids and asks in that paper.
} 
and a continuation probability of $90 \%$ thereafter. Subjects are aware of the minimum number of periods and the continuation probability. The random numbers were drawn prior to the experiment and the same number of extra periods (determined with this continuation probability) was used in all sessions of the indefinite treatments. This resulted in 4,3 , and 1 additional periods above the minimum in the three rounds, respectively. There are thus 17,16 , and 14 periods in the three rounds of short-indefinite and 32, 31, and 29 periods in the three rounds of long-indefinite.

\subsection{Procedures}

The experiment was programmed in $\mathrm{PhP} / \mathrm{MySql}$ and conducted at the CREED laboratory of the University of Amsterdam. In total, 192 subjects participated in the experiment throughout 11 sessions (9 groups in short-definite, 8 in short-indefinite, 7 in long-definite, and 8 in long-indefinite). Short sessions lasted on average around 105 minutes, with average earnings of 23.53 euros. Long sessions lasted on average around 160 minutes, with average earnings of 34.43 euros. The majority of subjects were economics students. At the beginning of the experiment, subjects read the instructions on paper at their own pace. Thereafter, they had to answer comprehension test questions on screen. They could not proceed to the first round of the experiment before all test questions were answered correctly. The experimental instructions and the comprehension test questions are reproduced in Online Appendix B. After the experiment, subjects completed a short post-experimental questionnaire to gather demographic information (age, gender, field of study, nationality). Subjects' earnings were determined based on their final cash holdings and asset holdings (bought back for 125 points per asset) at the end of a randomly chosen market round. They received 1 euro for each 800 points they earned. 


\section{Results}

Figures 1 and 2 show market prices in all treatments, separately for each round. Each line represents one group (interruptions of the lines correspond to periods without trade). Figure 3 shows the mean prices per group across all periods of a round. As the fundamental value in our markets is constant, and as almost all observed prices are above the fundamental value, the mean price is a good measure of both mispricing and overpricing (for other measures, see Stöckl et al., 2010).

Figures 1 to Figure 3 already reveal what will be confirmed in the statistical analyses below. Market prices are on average considerably above the fundamental value. In all treatments, there are reoccurring bubbles in several groups. With the definition from Kopányi-Peuker and Weber (2021) that there is a bubble in a market if the mean price is at least twice the fundamental value, there are 8,8 , and 7 bubbles in rounds 1,2 , and 3 , respectively, among the 9 groups in short-definite; among the 8 groups in short-indefinite, there are 7 bubbles in each round; in long-definite (7 groups), there are 6, 5, and 3 bubbles; in long-indefinite (8 groups), there are 6,5 , and 5 bubbles. ${ }^{4}$

No systematic differences are visible between the two treatments with short horizons (short-definite and short-indefinite) and between the two treatments with long horizons (long-definite and long-indefinite). Prices are, however, on average higher in the treatments with a short horizon than in the treatments with a long horizon. Except for this level effect of prices being higher in the short horizon treatments, patterns look very similar across all four treatments. Pricing is not much more accurate in later rounds than in earlier rounds, and the level of learning that does exist is not different across the treatments. Similarly, while there is some mild speeding up of bubbles (bubbles forming earlier in a round in later rounds of the experiment), the treatment has no sizable impact on this speeding up

\footnotetext{
${ }^{4}$ Note that this bubble definition is conservative in the sense that it relies on mean prices. The numbers would naturally be even higher if already the price in one period above twice the fundamental would be considered a bubble.
} 


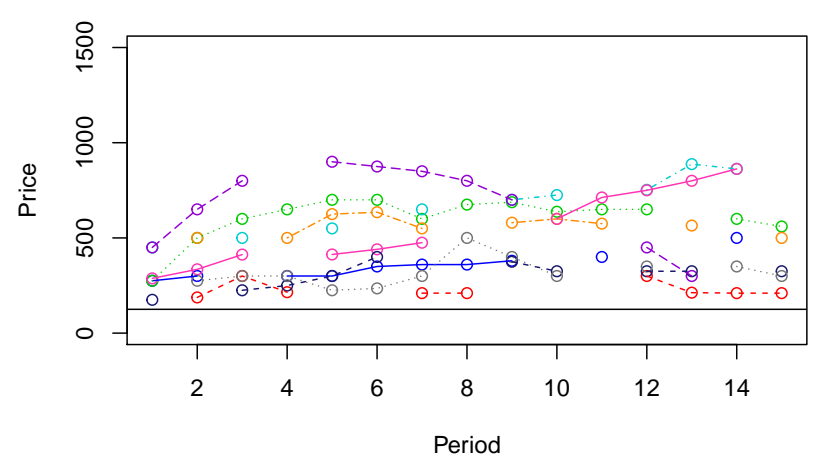

(a) short-definite Round 1

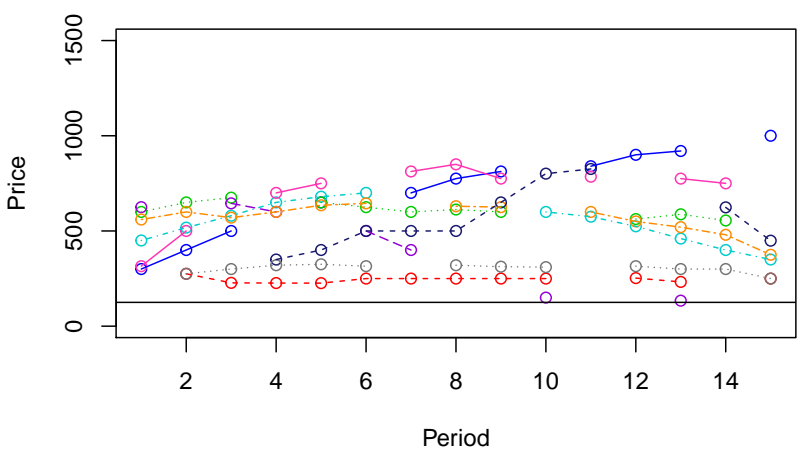

(c) short-definite Round 2

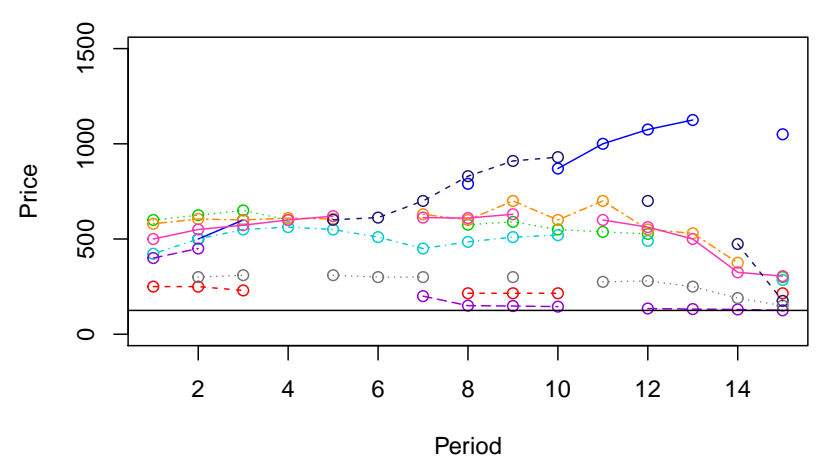

(e) short-definite Round 3

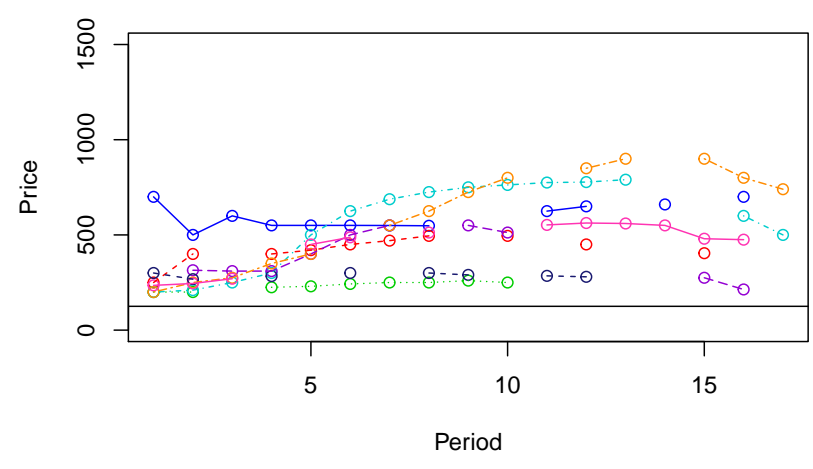

(b) short-indefinite Round 1

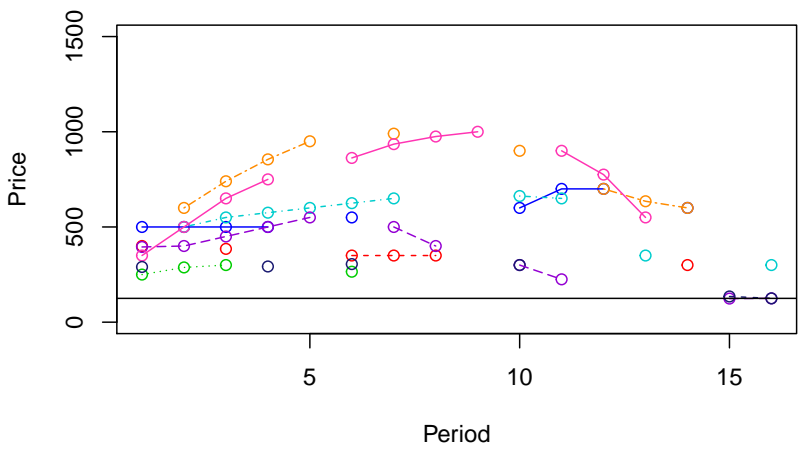

(d) short-indefinite Round 2

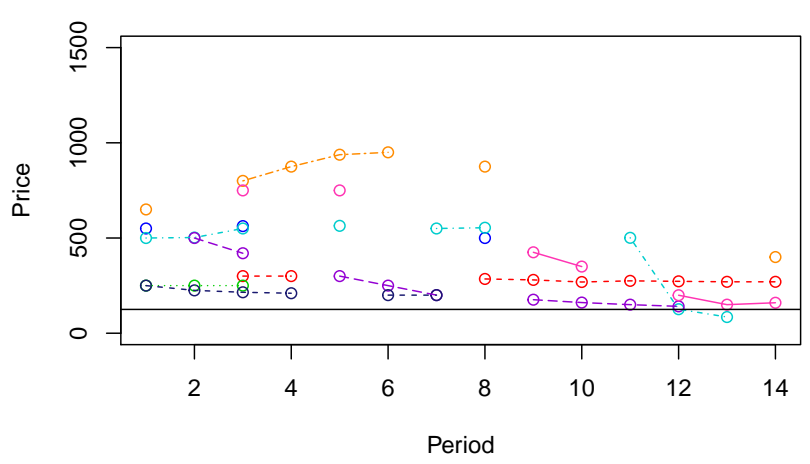

(f) short-indefinite Round 3

Figure 1: Market prices in treatments short-definite and short-indefinite

This figure shows prices in the treatments short-definite and short-indefinite in all rounds. Each color and line type represents one group. 


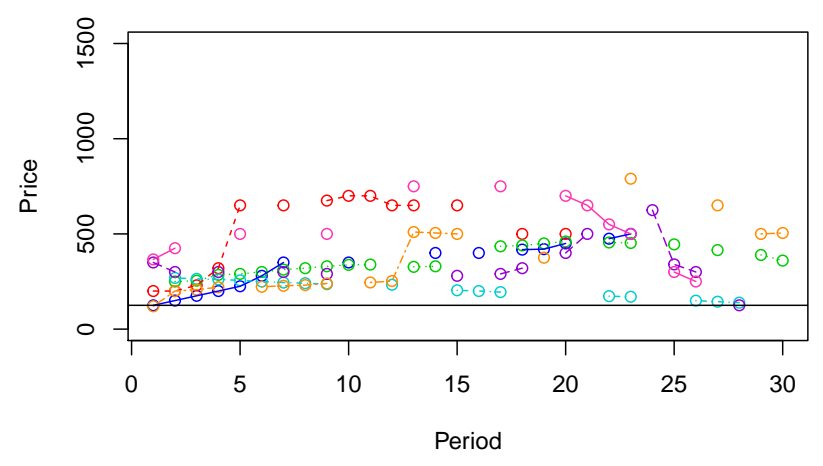

(a) long-definite Round 1

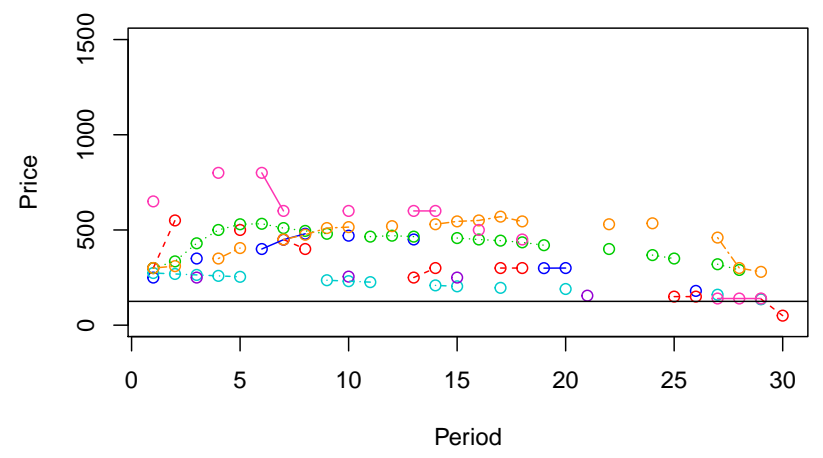

(c) long-definite Round 2

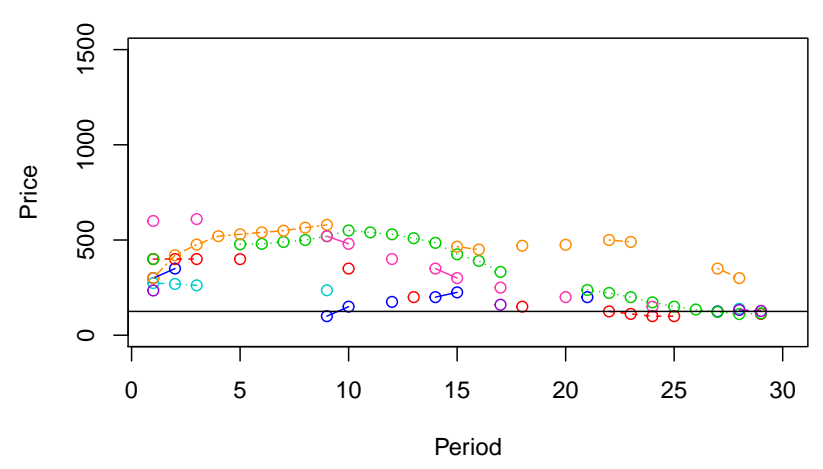

(e) long-definite Round 3

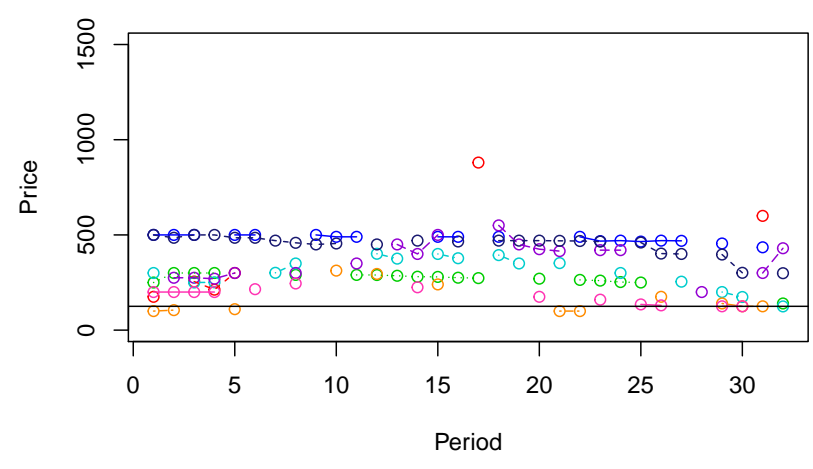

(b) long-indefinite Round 1

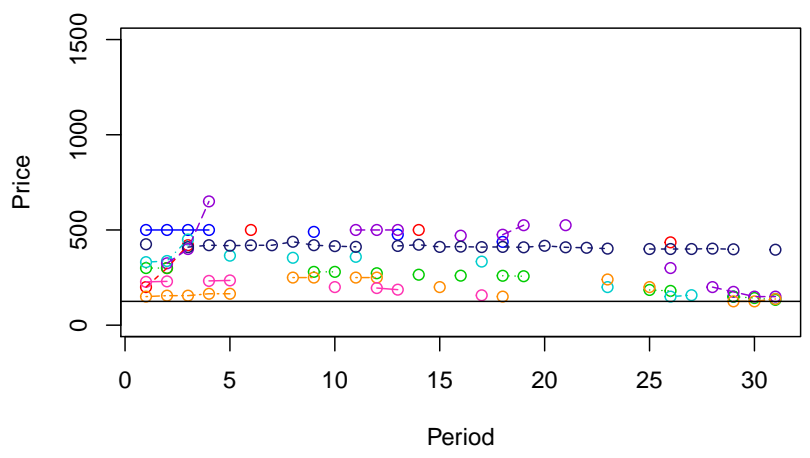

(d) long-indefinite Round 2

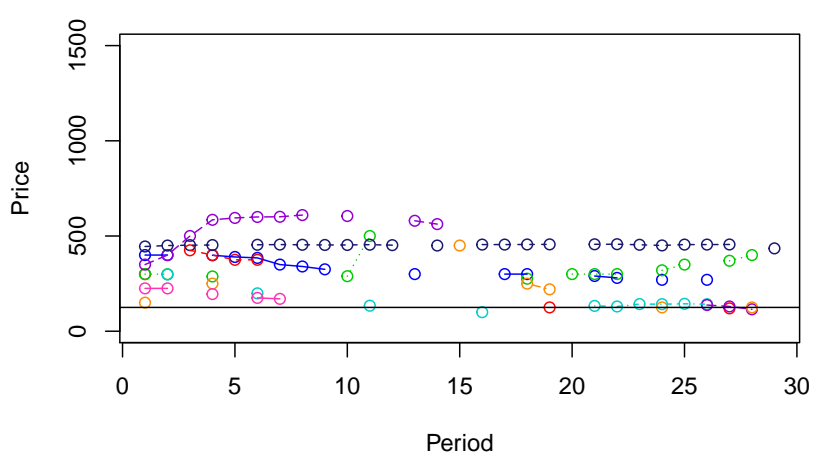

(f) long-indefinite Round 3

Figure 2: Market prices in treatments long-definite and long-indefinite

This figure shows prices in the treatments long-definite and long-indefinite in all rounds. Each color and line type represents one group. 


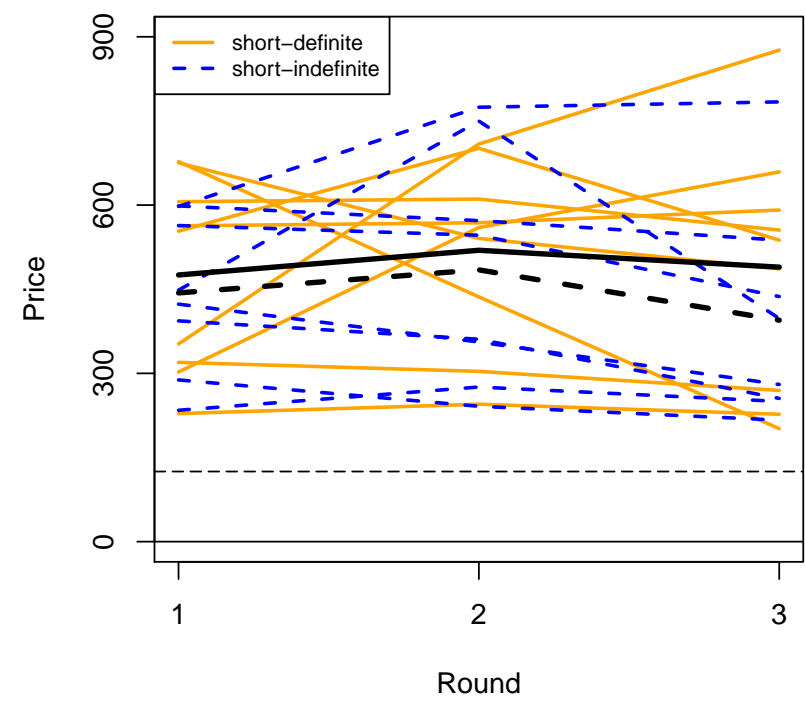

(a) short treatments

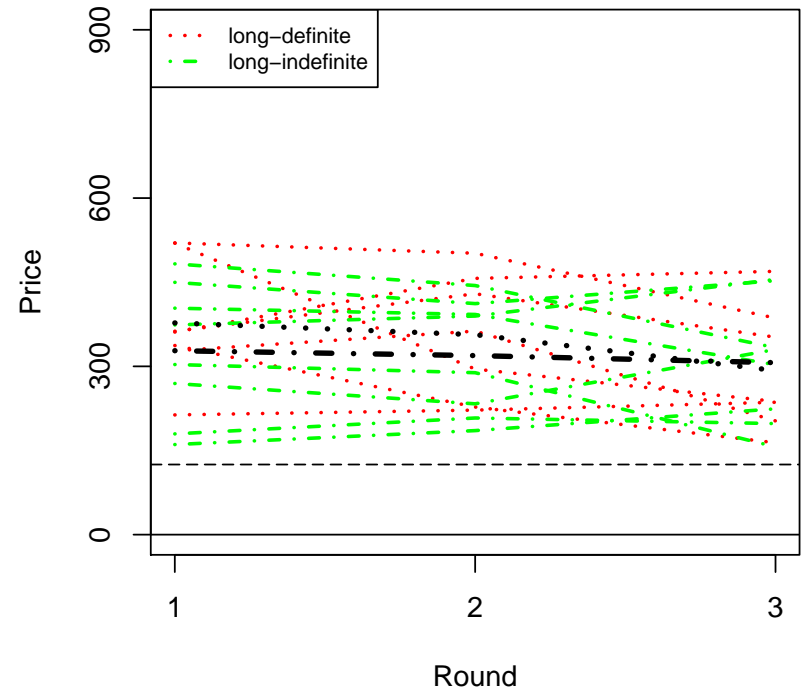

(b) long treatments

Figure 3: Mean prices in all treatments and rounds

This figure shows the mean market prices across all periods of a round. Each thin colored line corresponds to one group. Thick black lines represent the mean values of these lines per treatment.

of bubbles.

\subsection{Overpricing}

We provide linear regression results to see whether the differences in overpricing observed in Figures 1 to Figure 3 are statistically significant and indeed systematic treatment differences. The dependent variable is the mean price per group, there is thus a total of 32 observations for all of the reported regressions. The groups do not interact with other groups in any way, so that the observations are statistically independent. The results are shown in Table 1. The upper half of the table provides coefficients of dummy variables for the long treatments (Long) and the indefinite treatments (Indefinite), without an interaction term. The coefficients are reported separately for each round and for the average across all three rounds. Half of the regressions do not include demographic covariates, the other half includes the demographic covariates age (average age in a group), gender 
(measured by the number of females in a group) and field of study (measured by the number of economics or business students in a group). All regressions include an intercept. The lower half of the table reports coefficients of the same regressions but including an interaction term of treatment variations Long and Indefinite. The full regression results including the intercept and coefficients of the control variables can be found in Tables C.1 and C.2 in the online appendix.

Table 1 shows that whether the horizon is definite or indefinite does not affect the pricing of the assets. In particular, prices are not higher in the indefinite treatments (they are on average slightly lower, without being significantly different from zero). ${ }^{5}$ The fact that backward induction is more difficult with indefinite horizons does thus not seem to be important for the pricing of the assets. One may also argue that backward induction is more difficult in the treatments with more periods. However, the difficulty of backward induction similarly does not lead to higher prices in the long treatments. In contrast, prices in the long treatments are significantly lower than in the short treatments. Depending on the regression specification, the effect that can be attributed to the length round is about $100-200$ points. As the fundamental value of the asset is 125 points and average prices are around 450 in the short treatments and a bit above 300 in the long treatments, this difference is considerable. However, the difference is not large enough to lead to accurate pricing in the long treatments. Also the treatments with long horizons price the assets much above the fundamental on average, with recurring bubbles also with experienced participants. ${ }^{6}$

These results are robust. Using maximal prices in a round as measure for over- or mispricing instead of mean prices, does not change the conclusion. Similarly, taking mean

\footnotetext{
${ }^{5}$ This finding relates to a finding in a different setting: comparing hard-close auctions (with definite ending) and sudden-termination auctions (with indefinite ending), Füllbrunn and Sadrieh (2012) do not find efficiency differences between the two auction mechanisms.

${ }^{6}$ Prices that are considerably above the fundamental value not only in the first but also in later periods have also been found by Kopányi-Peuker and Weber (2021) for a variety of information treatments in call markets (with high cash-to-asset ratio) and learning-to-forecast markets.
} 


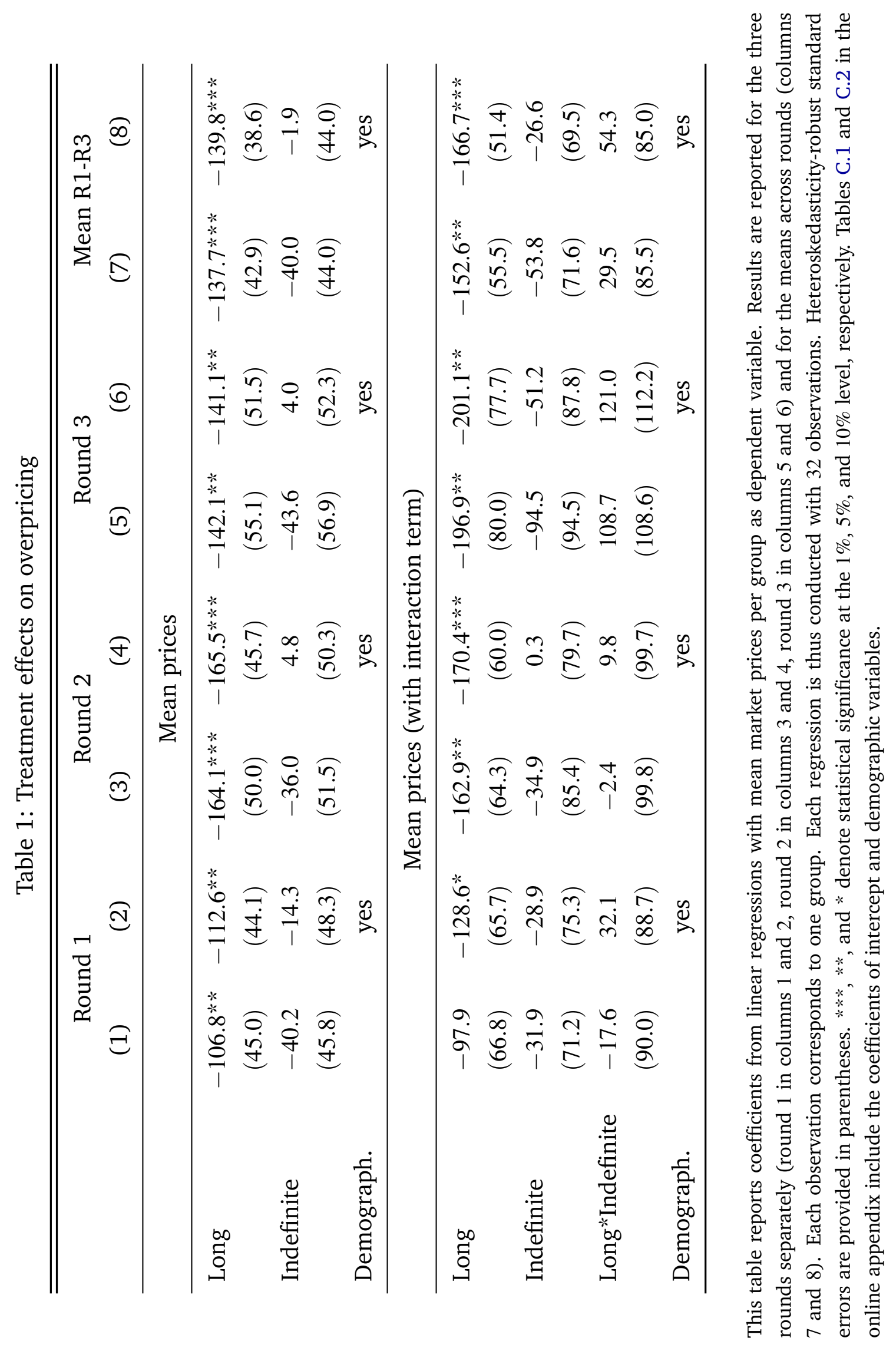


prices in only the first ten periods of each round does not change our conclusions. These robustness checks can be found in Tables C.3 to C.6 in the online appendix.

\subsection{Learning and Speeding up of Bubbles}

Not only the extent of overpricing is interesting, but the dynamics of prices are also of great interest. Do participants learn to price the assets well with experience? Do bubbles appear earlier in later rounds of the experiment? Figures 1 to Figure 3 suggest that prices do not become considerably more accurate across the rounds, with at best slight decreases in overpricing during the course of the experiment in all treatments. Similarly, the shapes of the bubbles look similar in all treatments and do not change much across the rounds. In particular there seem to be no treatment differences with respect to the speeding up of bubbles (that is, bubbles appearing in earlier periods of later rounds). Regression results confirm these impressions, as shown in Table 2.

The upper part of Table 2 provides coefficients for the treatment variables with the dependent variable 'mean prices R1 minus mean prices R3'. If participants learn to price the assets better over the rounds, mean prices should decrease across rounds, so that this number is positive. Looking at the mere means instead of regressions, there is only very limited learning. On average, pricing worsens by 14 points in short-definite and improves by 49 (short-indefinite), 85 (long-definite), and 22 (long-indefinite) points in the other treatments. These numbers are not statistically significant (neither when conducting Wilcoxon signedrank tests per treatment nor when looking at the intercepts of regressions, as reported in Table C.7 in the online appendix). ${ }^{7}$ The regressions in the upper part of Table 2 further reveal that there are no significant treatment differences concerning the learning of asset prices, with or without interaction term or the inclusion of demographic variables. ${ }^{8}$

\footnotetext{
${ }^{7}$ Very slow learning in call markets with high cash-to-asset ratio have similarly been observed in KopányiPeuker and Weber (2021).

${ }^{8}$ The results are robust to using the difference in maximal prices rather than mean prices. The results of this robustness check can be found in Table C.8 in the online appendix.
} 
Table 2: Treatment effects on learning and speeding up of bubbles

\begin{tabular}{|c|c|c|c|c|}
\hline & (1) & (2) & (3) & (4) \\
\hline \multicolumn{5}{|c|}{ Mean prices R1 minus R3 (learning) } \\
\hline Long & $\begin{array}{c}35.3 \\
(57.2)\end{array}$ & $\begin{array}{c}98.9 \\
(101.9)\end{array}$ & $\begin{array}{c}28.4 \\
(60.7)\end{array}$ & $\begin{array}{c}72.6 \\
(105.1)\end{array}$ \\
\hline Indefinite & $\begin{array}{c}3.4 \\
(59.3)\end{array}$ & $\begin{array}{c}62.6 \\
(97.7)\end{array}$ & $\begin{array}{l}-18.3 \\
(53.6)\end{array}$ & $\begin{array}{c}22.2 \\
(93.2)\end{array}$ \\
\hline Long*Indefinite & & $\begin{array}{l}-126.3 \\
(112.7)\end{array}$ & & $\begin{array}{c}-88.9 \\
(118.8)\end{array}$ \\
\hline Demograph. & & & yes & yes \\
\hline \multicolumn{5}{|c|}{$\begin{array}{l}\text { Mean prices in first half of round as fraction of mean } \\
\text { prices in round, R3 minus R1 (speeding up of bubbles) }\end{array}$} \\
\hline Long & $\begin{array}{c}0.02 \\
(0.09)\end{array}$ & $\begin{array}{l}0.19^{*} \\
(0.09)\end{array}$ & $\begin{array}{l}-0.02 \\
(0.08)\end{array}$ & $\begin{array}{c}0.14 \\
(0.09)\end{array}$ \\
\hline Indefinite & $\begin{array}{l}-0.03 \\
(0.09)\end{array}$ & $\begin{array}{c}0.13 \\
(0.13)\end{array}$ & $\begin{array}{c}0.06 \\
(0.09)\end{array}$ & $\begin{array}{c}0.21 \\
(0.13)\end{array}$ \\
\hline Long*Indefinite & & $\begin{array}{l}-0.34 * \\
(0.17)\end{array}$ & & $\begin{array}{l}-0.31 * \\
(0.16)\end{array}$ \\
\hline Demograph. & & & yes & yes \\
\hline
\end{tabular}

This table reports coefficients from linear regressions. The upper part shows regressions with the difference of mean prices between the first and last round as dependent variable. The lower part shows regressions with the following dependent variable: difference between the first and the last round of the mean price in the first half of a round divided by the mean price in the entire round. Each observation corresponds to one group. Each regression is thus conducted with 32 observations. Columnn (2) and (4) include an interaction term, columns (3) and (4) include demographic variables. Heteroskedasticity-robust standard errors are provided in parentheses. $* * *, * *$, and * denote statistical significance at the $1 \%, 5 \%$, and $10 \%$ level, respectively. Tables C.7 and C.9 in the online appendix include the coefficients of intercept and demographic variables. 
To see whether bubbles speed up over time, that is whether bubbles appear earlier in the last round of the experiment than in the first, we consider the following measure. We calculate the fraction of the mean price in the first half of a round (if the number of periods is odd, we round up) and divide it by the mean price in the whole round (similarly to Kopányi-Peuker and Weber, 2021). If bubbles appear earlier in later rounds, this measure should be higher in later than in earlier rounds. This is indeed what we observe in all treatments. ${ }^{9}$ This measure increases from 0.93 to 1.07 (short-definite), from 0.92 to 1.20 (short-indefinite), from 0.92 to 1.25 (long-definite), and from 1.02 to 1.14 (long-indefinite). ${ }^{10}$ The lower part of Table 2 shows that there are basically no treatment differences considering the speeding up of the bubbles (in one of the four shown specifications, there is a marginally significant positive coefficient for the treatment variable "Long" pointing to slightly faster speed up, and in two of the four specifications there is a marginally significant negative coefficient for the interaction term "Long*Indefinite").

\section{Concluding Remarks}

Despite the fact that there are already hundreds of scientific articles on experimental asset markets, there is thus far basically no literature analyzing the effect of definite end times and of the number of periods in a market in a controlled manner. This is surprising, as the definite and short horizons usually employed in the laboratory may be considered the greatest differences to actual financial markets. The current paper addresses this gap in the literature.

We find that price dynamics are overall very similar across the different treatments, independent of whether the horizon is short, long, definite, or indefinite (while levels of prices

\footnotetext{
${ }^{9}$ Such a speeding up of bubbles has already been observed in a variety of different market settings (e.g., King et al., 1993; Dufwenberg et al., 2005; Haruvy et al., 2007; Kopányi-Peuker and Weber, 2021).

${ }^{10}$ These differences are marginally significant in short-definite $(p=0.055)$, significant in short-indefinite ( $p=0.016)$ and long-definite ( $p=0.031)$, and insignificant in long-indefinite $(p=0.250)$, tested with Wilcoxon signed-rank tests.
} 
are similar in definite and indefinite treatments but moderately lower in long treatments). Bubbles recur in all treatments with only very slow increases in pricing accuracy across the repetitions of a market. Bubbles appear slightly earlier in later repetitions of the markets in all treatments, as generally observed in the literature.

We consider these findings to be good news for the large existing literature on experimental asset markets. Given that we observe such similar dynamics in the different treatments, it seems most likely that the qualitative findings from existing asset market experiments, in particular treatment differences, are not driven by the particular choice of the (usually short and definite) end time.

\section{References}

Ahrens, S., Bosch-Rosa, C., and Roulund, R. P. (2020). Asset price dynamics and endogenous trader overconfidence. Working Paper, Technical University of Berlin.

Asparouhova, E., Bossaerts, P., Roy, N., and Zame, W. (2016). "Lucas" in the laboratory. Journal of Finance, 71(6):2727-2780.

Bao, T., Hommes, C., and Makarewicz, T. (2017). Bubble formation and (in)efficient markets in learning-to-forecast and optimise experiments. The Economic Journal, 127(605):F581-F609.

Bosch-Rosa, C., Meissner, T., and Bosch-Domènech, A. (2018). Cognitive bubbles. Experimental Economics, 21(1):132-153.

Bossaerts, P. (2009). The experimental study of asset pricing theory. Foundations and Trends in Finance, 3(4):289-361.

Bossaerts, P., Ghirardato, P., Guarnaschelli, S., and Zame, W. R. (2010). Ambiguity in asset markets: Theory and experiment. Review of Financial Studies, 23(4):1325-1359. 
Charness, G. and Neugebauer, T. (2019). A test of the modigliani-miller invariance theorem and arbitrage in experimental asset markets. Journal of Finance, 74(1):493-529.

Cheung, S. L., Hedegaard, M., and Palan, S. (2014). To see is to believe: Common expectations in experimental asset markets. European Economic Review, 66:84-96.

Cheung, S. L. and Palan, S. (2012). Two heads are less bubbly than one: Team decisionmaking in an experimental asset market. Experimental Economics, 15(3):373-397.

Crockett, S., Duffy, J., and Izhakian, Y. (2019). An experimental test of the Lucas asset pricing model. Review of Economic Studies, 86(2):627-667.

Duffy, J., Jiang, J., and Xie, H. (2020). Experimental asset markets with an indefinite horizon. Working Paper, University of California, Irvine.

Dufwenberg, M., Lindqvist, T., and Moore, E. (2005). Bubbles and experience: An experiment. American Economic Review, 95(5):1731-1737.

Fenig, G., Mileva, M., and Petersen, L. (2018). Deflating asset price bubbles with leverage constraints and monetary policy. Journal of Economic Behavior \& Organization, 155:127.

Füllbrunn, S., Rau, H. A., and Weitzel, U. (2014). Does ambiguity aversion survive in experimental asset markets? Journal of Economic Behavior \& Organization, 107:810826.

Füllbrunn, S. and Sadrieh, A. (2012). Sudden termination auctions-an experimental study. Journal of Economics \& Management Strategy, 21(2):519-540.

Haruvy, E., Lahav, Y., and Noussair, C. N. (2007). Traders' expectations in asset markets: Experimental evidence. American Economic Review, 97(5):1901-1920.

Hens, T. and Steude, S. C. (2009). The leverage effect without leverage. Finance Research Letters, 6(2):83-94. 
Holt, C. A., Porzio, M., and Song, M. Y. (2017). Price bubbles, gender, and expectations in experimental asset markets. European Economic Review, 100:72-94.

Hommes, C., Kopányi-Peuker, A., and Sonnemans, J. (2021). Bubbles, crashes and information contagion in large-group asset market experiments. Experimental Economics, 24(2):414-433.

Hoshihata, T., Ishikawa, R., Hanaki, N., and Akiyama, E. (2017). Flat bubbles in longhorizon experiments: Results from two market conditions. GREDEG Working Paper No. 2017-32.

Huber, J. and Kirchler, M. (2012). The impact of instructions and procedure on reducing confusion and bubbles in experimental asset markets. Experimental Economics, 15(1):89-105.

King, R. R., Smith, V. L., Williams, A. W., and van Boening, M. (1993). The robustness of bubbles and crashes in experimental stock markets. In Day, R. H. and Chen, P., editors, Nonlinear Dynamics and Evolutionary Economics, pages 183-200. Oxford University Press, New York.

Kirchler, M., Huber, J., and Stöckl, T. (2012). Thar she bursts: Reducing confusion reduces bubbles. American Economic Review, 102(2):865-883.

Kopányi-Peuker, A. and Weber, M. (2021). Experience does not eliminate bubbles: Experimental evidence. Review of Financial Studies. Forthcoming.

Lahav, Y. (2011). Price patterns in experimental asset markets with long horizon. Journal of Behavioral Finance, 12(1):20-28.

Lambrecht, M., Sofianos, A., and Xu, Y. (2021). Does mining fuel bubbles? An experimental study on cryptocurrency markets. 
Noussair, C. N., Tucker, S., and Xu, Y. (2016). Futures markets, cognitive ability, and mispricing in experimental asset markets. Journal of Economic Behavior and Organization, $130: 166-179$.

Palan, S. (2010). Digital options and efficiency in experimental asset markets. Journal of Economic Behavior \& Organization, 75(3):506-522.

Palan, S. (2013). A review of bubbles and crashes in experimental asset markets. Journal of Economic Surveys, 27(3):570-588.

Powell, O. and Shestakova, N. (2016). Experimental asset markets: A survey of recent developments. Journal of Behavioral and Experimental Finance, 12:14-22.

Razen, M., Huber, J., and Kirchler, M. (2017). Cash inflow and trading horizon in asset markets. European Economic Review, 92:359-384.

Stöckl, T., Huber, J., and Kirchler, M. (2010). Bubble measures in experimental asset markets. Experimental Economics, 13(3):284-298.

Sutter, M., Huber, J., and Kirchler, M. (2012). Bubbles and information: An experiment. Management Science, 58(2):384-393.

Tucker, S. J. and Xu, Y. (2020). Nonspeculative bubbles revisited: Speculation does matter. Working Paper, University of Waikato.

Weber, M., Duffy, J., and Schram, A. (2018). An experimental study of bond market pricing. Journal of Finance, 73(4):1857-1892.

Weber, M., Duffy, J., and Schram, A. (2019). Credit default swap regulation in experimental bond markets. Tinbergen Institute Discussion Paper No 2019-039/I.

Weitzel, U., Huber, C., Huber, J., Kirchler, M., Lindner, F., and Rose, J. (2020). Bubbles and financial professionals. Review of Financial Studies, 33(6):2659-2696. 


\title{
Online Appendix to "The Role of the End Time in Experimental Asset Markets"
}

\author{
Anita Kopányi-Peuker
}

\author{
Matthias Weber
}

This online appendix contains material in addition to the main text. Section A contains the screenshot of the decision task in the experiment. Section B reproduces the experimental instructions and comprehension test questions for the different treatments. Regression results and robustness checks can be found in Section C.

\section{A Screenshot}

Figures A.1 shows a screenshot for subjects' decision in treatment short-definite. Screens in other treatments only differ in the graph in the lower left part of the screen. The predetermined $x$-axis was the number of periods in a given round for the definite treatments, whereas it was the minimum number of periods, or if it passed, all past periods in the indefinite treatments. 

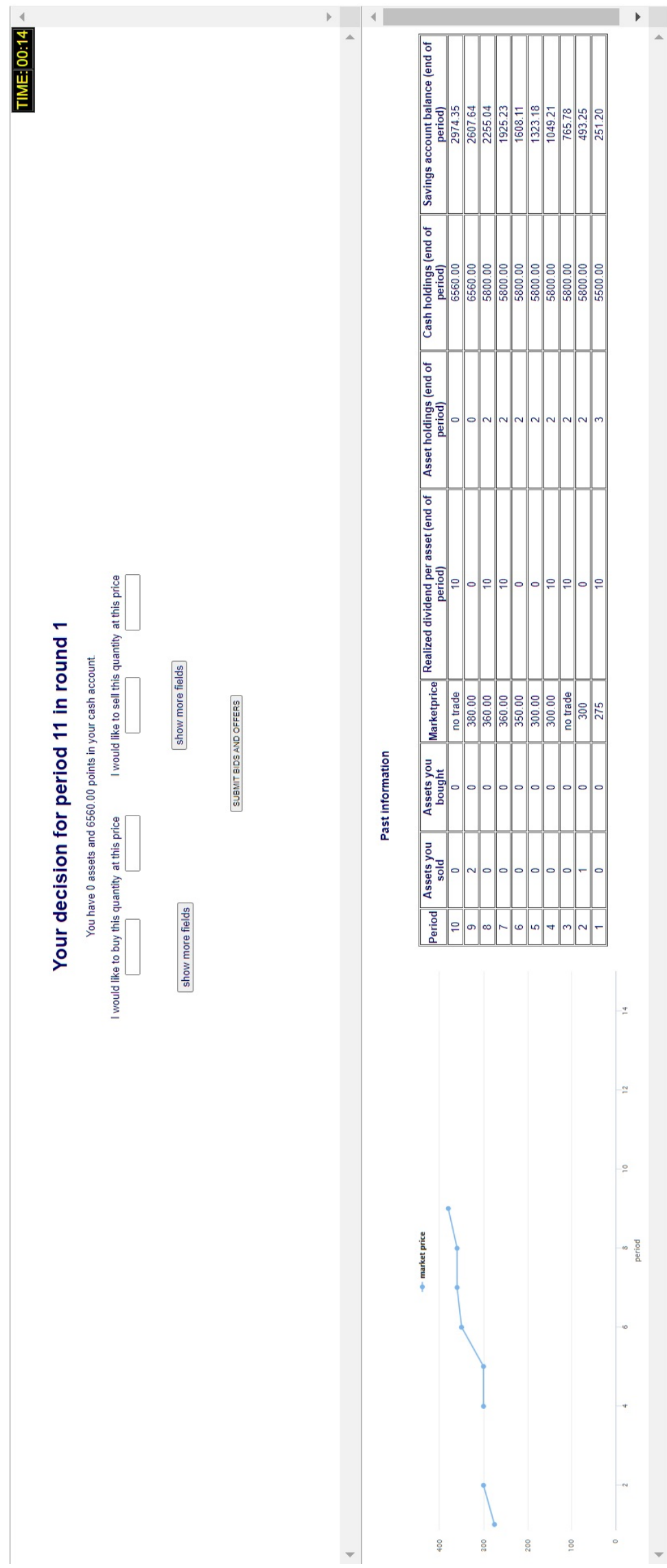

Figure A.1: Decision screen 


\section{B Experimental Instructions}

We reproduce the complete experimental instructions for the treatment short-definite in Section B.1. Bold or italic text is also bold or italic in the original instructions and text in boxes is similarly in such boxes in the original instructions. In Section B.2 we discuss the differences in instructions between the treatments. Section B.3 reproduces the comprehension test questions as used in treatment short-definite. Section B.4 reports the difference in the test questions used in the other treatments.

Note that the numbers used as examples in the instructions are more often above the fundamental value than below. However, the opposite is true in the comprehension test questions, so that no considerable anchoring bias should arise from the examples if instructions and comprehension test questions are considered jointly.

\section{B.1 Instructions for treatment short-definite}

\section{Welcome to this experiment!}

Please read these instructions carefully as they explain how you earn money from the decisions that you make. You will be paid privately at the end, after all participants have finished the experiment.

During the experiment you are not allowed to use your mobile phone or other electronic devices. You are also not allowed to communicate with other participants. If you have a question at any time, please raise your hand and someone will come to your desk to answer your question in private.

The experiment consists of 3 identical rounds. Each round consists of 15 periods. Your earnings for each of the 3 rounds will be in points. At the end, only your earnings from one randomly selected round will be paid out to you! The points from the selected 
round will be exchanged into euros at the exchange rate 800 points $=1$ euro. In addition you will receive 10 euros for your participation.

All participants will be randomly divided into groups of 6 people. The group composition will not change during the experiment. You will not know the identity of any group member nor will they know your identity even after the experiment is over.

The following describes what you will be doing in each of the 3 rounds.

\section{General information}

You will be given an opportunity to trade in an asset with the other participants in your group. You will start each round with an endowment of 5500 points (booked on your "cash account") and with 3 assets. In total there are 18 identical assets that you can trade. Holding assets can give you earnings in a way that will be explained below. Each round consists of 15 time periods in which you can trade.

\section{Trading}

If you want to buy assets, you can enter the number of assets that you want to buy (bid for) at a certain price using the computer interface. You can state as many different bid prices and quantities as you like.

Example (the numbers here provide no indication of what you should enter in the experiment): Imagine that you would like to buy no assets if the price per asset is more than 200 points. If the price is at most 200 but more than 150 points, you would like to buy one asset. If the price of the asset is at most 150 points, you would like to buy four assets altogether. Then you should enter the following information:

- One bid for 1 asset with a price of 200

- One bid for 3 assets with a price of 150

Note: At a price of less than 150 you want to buy four assets - nevertheless, the quantity that you enter with the price of 150 should be only three in this case. This is so, because you are already bidding for one asset at a price of up to 200 . 
If you want to sell assets that you previously bought (or assets that you are endowed with in the beginning of a round), then you can do something similar. You enter the number of assets that you want to sell (offer quantity) and the ask price (or offer price), which is the minimum price that you would like to receive for those units of the asset. You can again enter multiple combinations of quantities and prices.

Example (the numbers here provide no indication of what you should enter in the experiment): Imagine that you would like to sell none of your assets if the price per asset is below 100 points. If the price is at least 100 points, but less than 700 points, you would like to sell two assets. If the price of the asset is at least 700 points, you would like to sell three assets altogether. Then you should enter the following information: - One offer of 2 assets with a price of 100

- One offer for 1 asset with a price of 700

Note: At a price of at least 700 you want to sell three assets - nevertheless, the quantity that you enter with the price of 700 should be only one in this case. This is so, because you are already offering two assets at a price of at least 100 .

In each period, you may enter both buy and sell orders, only buy orders, only sell orders, or no orders at all.

In each period you have enough (but limited) time to submit your bids and offers. If you do not submit bids or offers during this time frame, the computer will consider this as no bids or offers. This means that if you have entered bids or offers into the computer interface but not submitted them by the time the period ends, these bids or offers will be lost. A timer will show you the remaining time for each period ( 2 minutes in the first 10 periods of the first round, 1 minute in all other periods).

The bids and offers that you can enter into the computer interface are restricted as follows:

- You can only enter positive integer number as quantities. 
- You can only enter positive numbers as prices (if you want to enter a decimal number, use a point and not a comma).

- You cannot try to sell more assets than you have at that moment. Similarly, you cannot try to buy more assets than there are available (which is 18 minus the number of assets you have).

- You cannot enter bids that you would not be able to pay for with the amount of cash that you have.

- All of your asks (offer prices) must be higher than your bids (that is, you cannot sell to yourself).

\section{Market Price and Traded Quantity}

The market price in each period is determined by supply and demand. This means that the price will be chosen that makes the most trades possible. All trades are then carried out at this single market price, which is centrally determined for your group in each period.

Explanation (this is a very simple example and the numbers here provide no indication of what you should enter in the experiment): Imagine you enter that you would like to buy 2 assets if the price is at most 550 points and one other participant enters that she would like to buy 4 assets if the price is at most 550. Imagine further that nobody else in the market enters a buying bid at 550 points or at a higher price. This means that all participants of the market together would like to buy 6 assets if the price is at most 550 points per asset. The aggregation of the buy orders can be done for all prices and yields the market demand schedule. This demand schedule contains the information of all buy orders for all participants of the market together and can be represented by a step function as below. On the horizontal axis you can see the total quantity demanded for each price on the vertical axis. In the graph of this simple example you can see that all participants of the market together are willing to buy up to 19 assets at a price of 80 points per asset, only 14 assets at a price of 300 points per asset, and only 6 assets 
at a price of 550 points per asset.

[Figure B.1 appears here in the experimental instructions.]

A similar schedule can be derived for the supply side of the market, aggregating all the sell offers. When drawn it in the same graph, the supply schedule is an increasing step function.

[Figure B.2 appears here in the experimental instructions.]

The market price is the price at which the two curves intersect (in this example 300). Similarly, the traded quantity is the quantity at which the two curves intersect (in this example 11). Note that at this price, 3 more assets are demanded than supplied (14 assets are demanded while only 11 are supplied). In this case a random selection of 3 bids from all the bids at the market price would not be fulfilled (it is similarly possible that there is more supply at the market price than demand).

In some rare cases there can also be a whole interval of prices at which the most trades can be carried out and the demand and supply schedules overlap vertically. In such cases the middle of the interval will be the market price. If no bids or offers are made at all or if all bids to buy are at lower prices than all offers to sell, there will be no trade and also no market price.

You will always see the market prices of previous periods in a round on your screen.

Similarly, you will see how many assets you bought or sold at this price. You will not be told the total number of trades in the market (except if there are none).

\section{Properties of the Asset and Interest Rate}

The financial asset pays a random dividend in each time period. This dividend is 10 points per asset with $50 \%$ probability and 0 points with $50 \%$ probability. In each period either all assets pay the high dividend or all assets pay the zero dividend. The dividend earnings 
will be paid to a separate account called "savings account" - they are part of your earnings for the round, but you cannot use points in this separate account to buy more assets.

The money that you do not spend on buying assets (and the money that you receive when selling assets) is stored in your cash account. You can use this money to buy more financial assets if you so wish. For the money in the cash account you receive an interest rate of $4 \%$ per time period. These interest earnings are not paid to the cash account but to the savings account.

Both dividends and interest rates will be paid "overnight"; this means that if you buy an asset in one period, you will have received your dividend from this asset by the time you are trading in the next period (similarly, the money that you hold after the trades of one period have been conducted will have yielded the interest by the time the trading of the next period begins). In the information table that you will see during the experiment, the dividend and interest payments following the trading of one period will already be included in the fields showing cash and savings account balance at the end of this period. The points in your savings account cannot be used to buy assets, but they still yield interest. The interest rate for the money in the savings account is the same as for the money in the cash account, namely $4 \%$. The interest is paid to the savings account at the same moment as the interest for the money in the cash account.

A round ends after period 15 . When a round ends, the financial asset ceases to exist and you receive 125 points per asset that you hold. A round always ends right after the dividend and interest payment for period 15.

You can now start to answer the comprehension questions on the screen. 


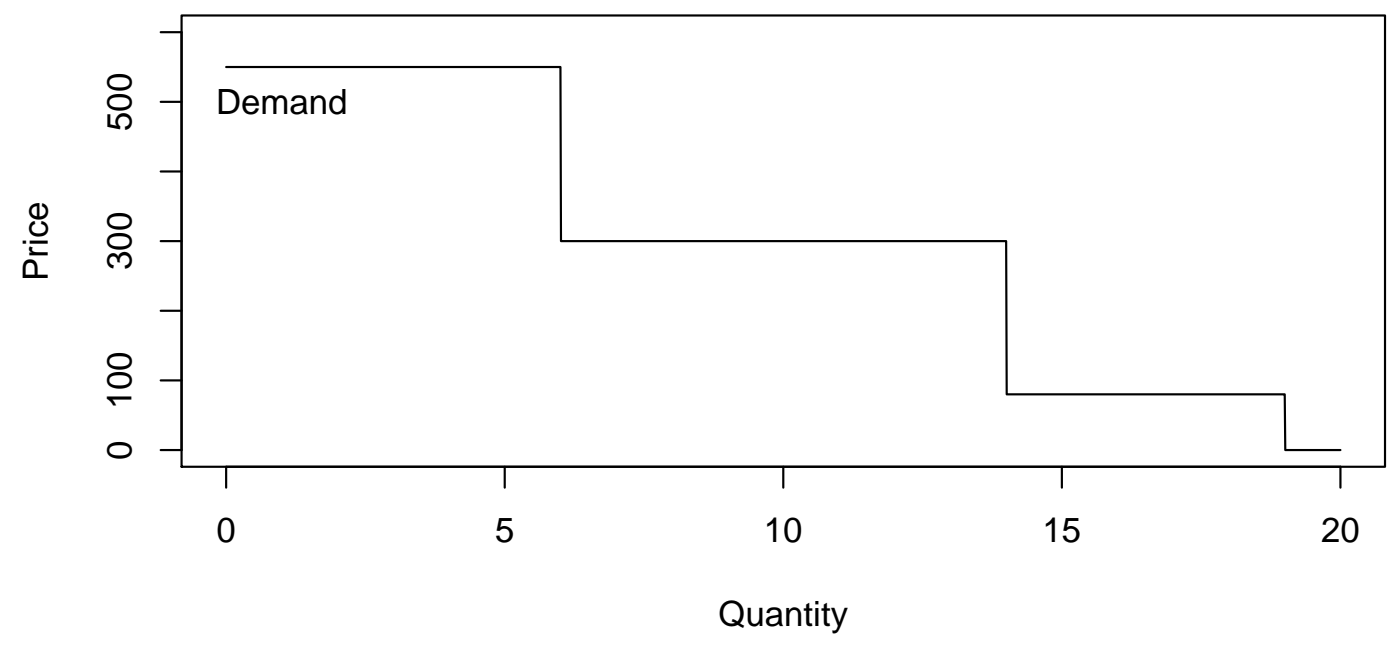

Figure B.1: Example of a demand curve (not labeled in the experimental instructions)

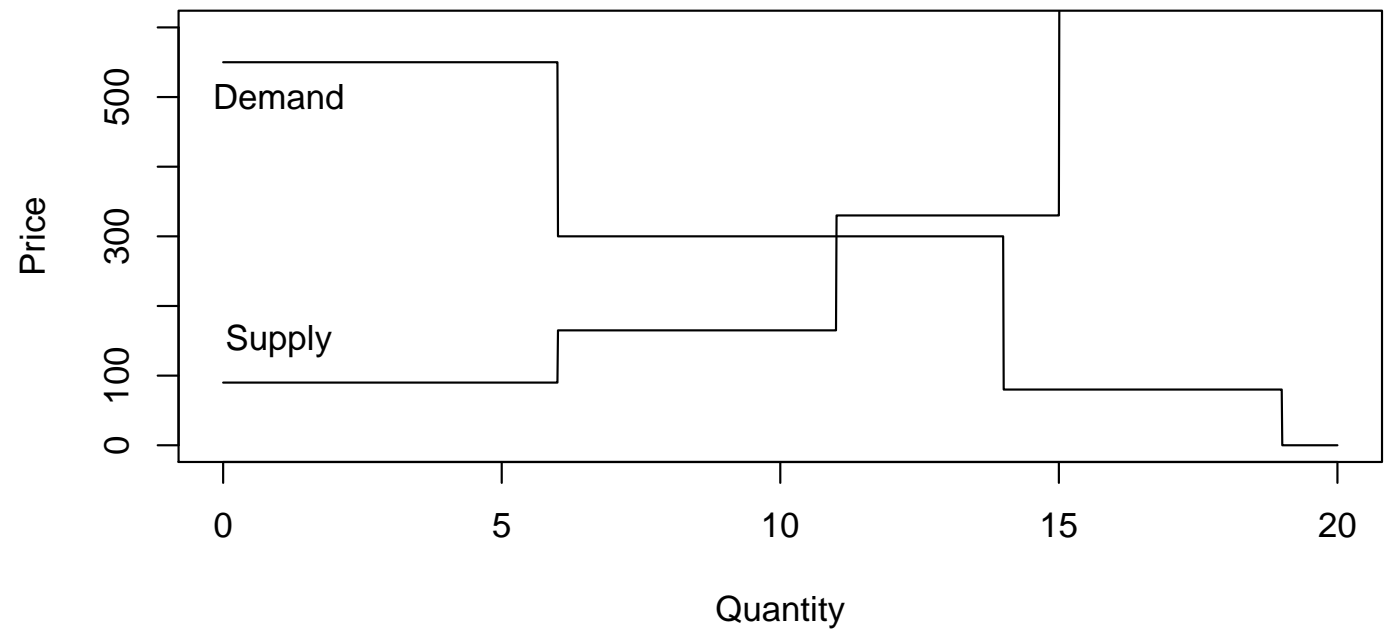

Figure B.2: Example of demand and supply curves (not labeled in the experimental instructions) 


\section{B.2 Differences in instructions between the treatments}

The instructions in the treatment long-definite are identical to those in short-definite except for the number of periods per round. Whenever we use 15 periods in treatment shortdefinite, we use there 30 periods in treatment long-definite:

- The last sentence of section "General information" reads as "Each round consists of 30 time periods in which you can trade."

- The last paragraph before the comprehension questions reads as follows: "A round ends after period 30. When a round ends, the financial asset ceases to exist and you receive 125 points per asset that you hold. A round always ends right after the dividend and interest payment for period 30."

The instructions for the indefinite treatments also mainly differ in the number of periods per round.

- In the introduction the sentences "The experiment consists of 3 identical rounds. Each round consists of 15 periods." read as "The experiment consists of 3 rounds. Each round consists of multiple periods. Except for the number of periods in each round, the rounds are identical." in both indefinite treatments.

- In "General information" the last sentence changes, and we add an extra sentence:

- Treatment short-indefinite: "Each round consists of multiple time periods in which you can trade. However, you do not know the exact number of time periods (there are at least 13 periods per round; you will receive more information on this below)."

- Treatment long-indefinite: almost identical to short-indefinite, but there are 28 periods instead of 13 .

- The last paragraph before the comprehension questions changes:

- Treatment short-indefinite: "There are at least 13 periods per round. After period 13, it is randomly determined whether another period takes place or whether 
the round ends. The probability that another period takes place is $90 \%$, while the probability is $10 \%$ that the round ends (after each new period it is then determined randomly whether another period takes place with the same probability of 90\%). You will not be explicitly informed about the outcome of this random draw each time: the round will just continue as before until the random draw leads to the end of the round; only then will you be informed that the round ended. When a round ends, the financial asset ceases to exist and you receive 125 points per asset that you hold. A round always ends right after the dividend and interest payment for the last period in which you could trade."

- Treatment long-indefinite: almost identical to short-indefinite, but there are 28 periods instead of 13 .

\section{B.3 Comprehension Test Questions}

We reproduce here the comprehension test questions in the treatment short-definite. The test questions are numbered on the screens and appear on two screens (the first four questions on the first screen). Note that subjects had to answer all questions on a screen correctly to proceed. If they did not answer all questions correctly and tried to proceed, they received the following error message: "You did not answer all questions correctly. Take another look at the instructions or raise your hand if you need help." We add a checkmark after each correct answer (or give the correct answer in brackets if the question is not a multiple choice problem). In Section B.4 we discuss how the test questions in the other treatments differ from those shown here.

1. Imagine the following situation. You want to buy 8 assets in total if the price is at most 30 points per asset. You want to buy 5 assets in total if the price is above 30 points but at most 100 points. You want to buy 1 asset if the price is above 100 
points but at most 311.5 points. What do you enter in the corresponding part of the computer interface?

a. Quantity: 8, Price: 30; Quantity: 5, Price: 100; Quantity: 1, Price: 311.5.

b. Quantity: 3, Price: 30; Quantity: 4, Price: 100; Quantity: 1, Price: 311.5. $\checkmark$

2. Imagine the following situation. All members in your group except for you offer to sell 2 assets at a price of 50 . You bid to buy 5 assets at a price of 200. Which of the following is the result of this?

a. The market price will be 50 . You will buy 5 assets at this price. Which 5 of the 10 assets offered at this price will be traded is determined randomly. $\checkmark$

b. The market price will be 200 . You will buy 5 assets at this price. Which 5 of the 10 assets offered at this price will be traded is determined randomly.

c. The market price will be 125 . You will buy 10 assets at this price.

3. You can enter bids to buy assets and offers to sell assets. Imagine that you consider both, buying and selling assets. Which of the following is correct?

a. You can try to bid for as many assets as you like at any price. If the market price turns out to be high, your cash holdings may become negative.

b. You cannot try to buy assets at a higher price than the lowest price at which you are willing to sell assets. $\checkmark$

4. Suppose that you earn 24000 points in the round that is randomly selected for payment. How much is that in euros?

- [Correct answer: 30]

5. Are the 3 rounds of the experiment different?

a. No, they are absolutely identical. $\checkmark$

b. Yes, they are different in a variety of aspects.

6. What happens if you have not submitted your bids and offers when the time of a period elapses?

a. The computer will automatically submit the bids and offers that you have en- 
tered into the computer interface (but not yet submitted).

b. The computer will not consider any bids or offers from you for this period. $\checkmark$

7. Which of the following is true about the savings account?

a. Points in the savings account do not yield any interest.

b. Points in the savings account cannot be used to buy assets. $\checkmark$

c. Points in the savings account do not count towards your round earnings.

8. Each round is terminated after period 15. When the round is terminated, how are your round earnings determined?

a. They depend on your points in the cash and interest accounts. Assets are worthless at the moment that the round terminates.

b. They depend on your points in the cash and savings accounts and on the points that you receive for the assets that you hold when the round terminates (125 points per asset). $\checkmark$

c. They depend only on your points in the cash account and on the last market price of the assets that you hold when the round terminates.

\section{B.4 Differences in comprehension test questions between the treat- ments}

The test questions and correct answers in the other three treatments are almost identical to those presented in B. 3 for treatment short-definite. Test question 8 is different for all four treatments, with answer b always being the correct answer. The difference between the treatments is as follows:

- short-definite: "Each round is terminated after period 15. When the round is terminated, how are your round earnings determined?"

- long-definite: "Each round is terminated after period 30. When the round is terminated, how are your round earnings determined?" 
- short-indefinite: "Each round is terminated abruptly somewhere after period 13. When the round is terminated, how are your round earnings determined?"

- long-indefinite: "Each round is terminated abruptly somewhere after period 28. When the round is terminated, how are your round earnings determined?"

Furthermore, for treatments short-indefinite and long-indefinite question 5 has a third answer possibility: "c. They might only differ in the number of periods per round, otherwise they are identical." The other two answers, a and b are identical to the answers in shortdefinite. Answer $\mathrm{c}$ is the correct answer in these indefinite treatments. 


\section{Full Regression Results and Robustness Checks}

\section{C.1 Overpricing}

Figure C. 1 shows maximal prices in each round for each group. Each group is represent by one colored thin line, averages across group per treatment are shown with thick black lines.

Tables C.1 and C. 2 show the full regression results with mean prices as dependent variable (the coefficient estimates of the treatment variables are contained in Table 1 in the main text). Tables C. 3 and C. 4 show the same regressions with maximal prices as dependent variable. Tables C.5 and C.6 show the regression with the mean in the first ten periods of each round as dependent variable.

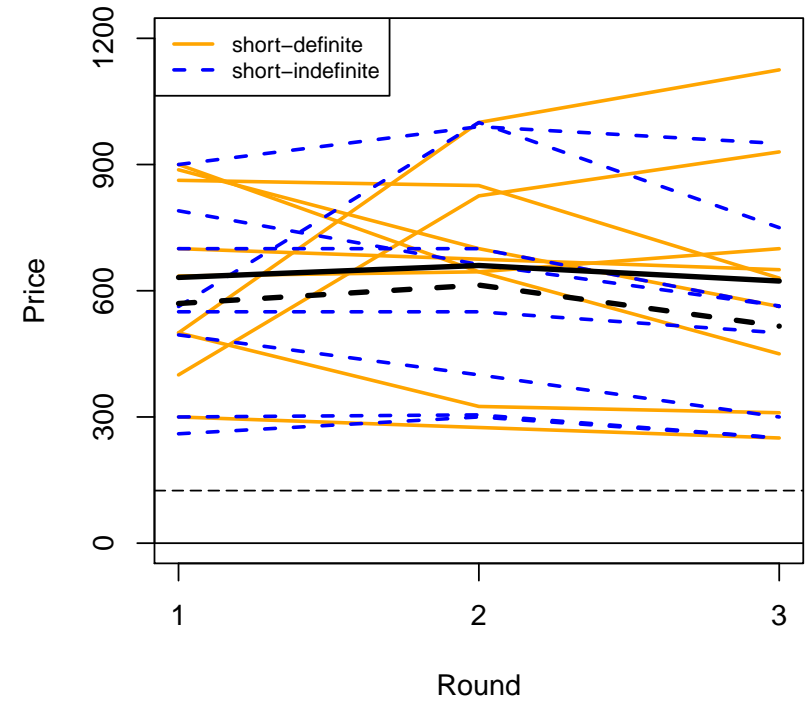

(a) short treatments

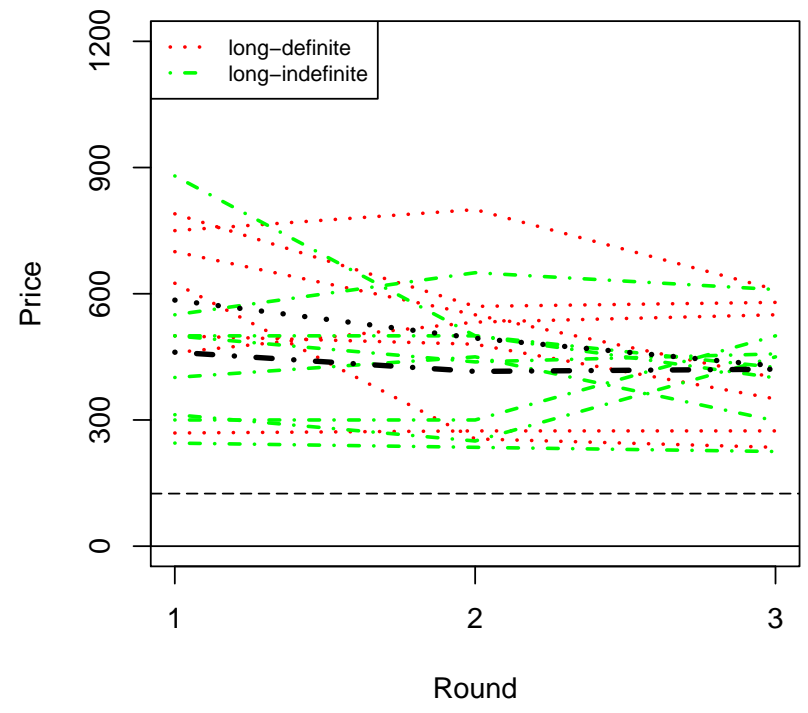

(b) long treatments

Figure C.1: Maximal prices in all treatments and rounds

This figure shows the maximal market prices in a round. Each thin colored line corresponds to one group. Thick black lines represent the mean values of these lines per treatment. 


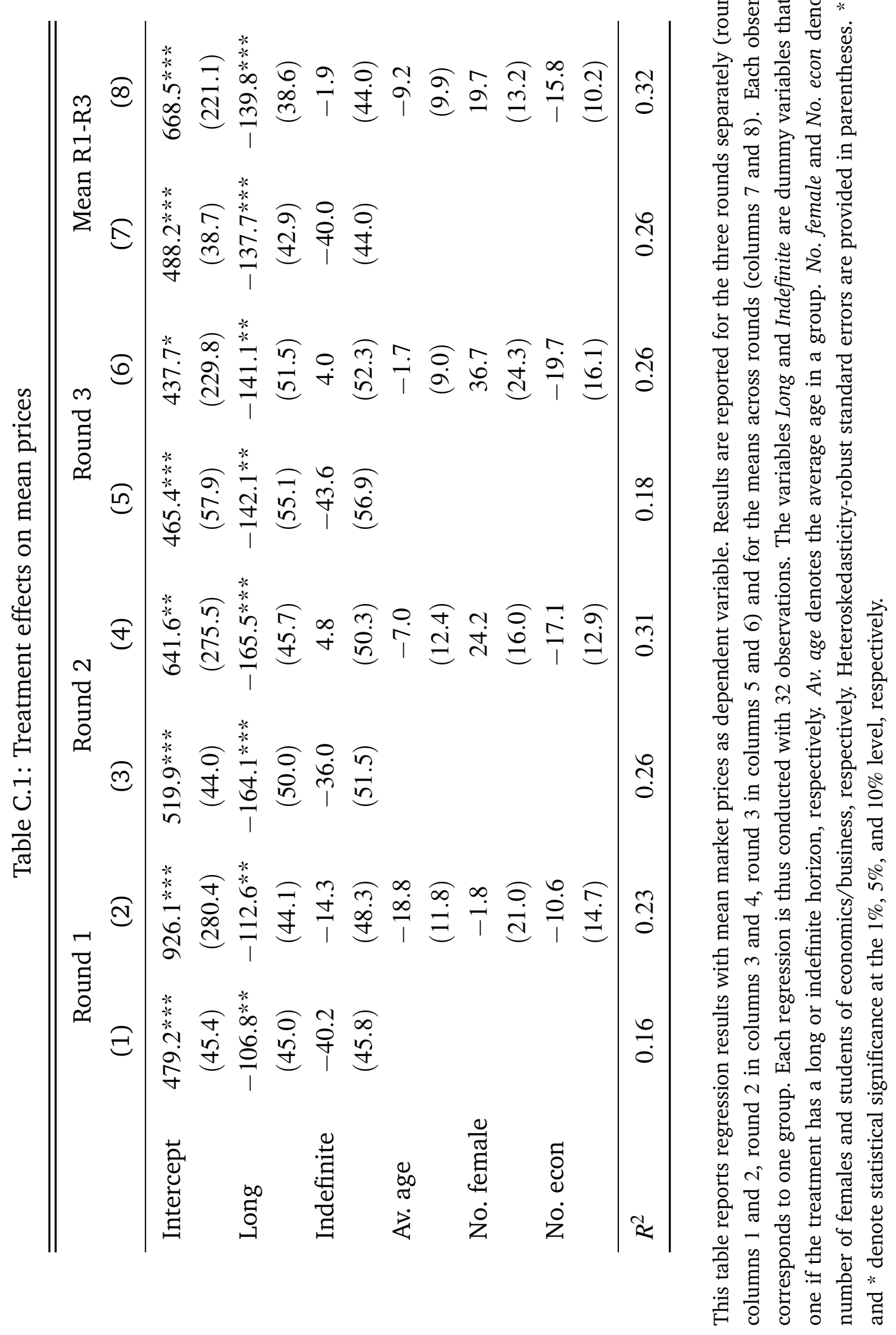




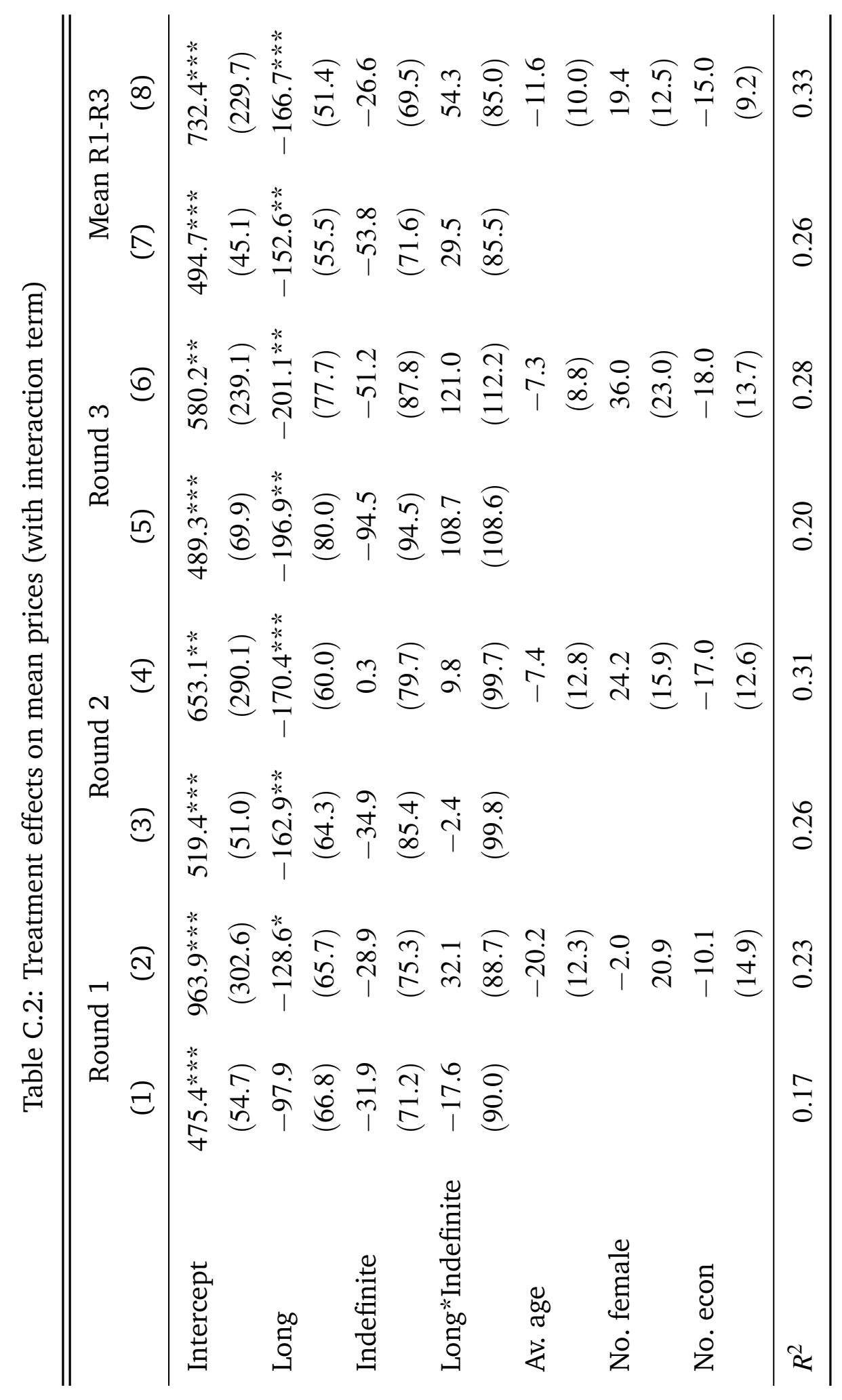

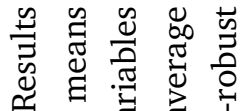

呅

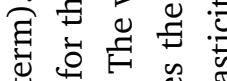

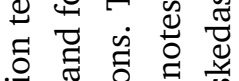

6 造

啳

चा n०े से से

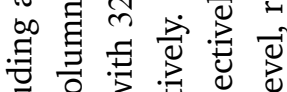

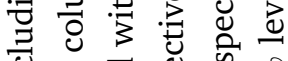

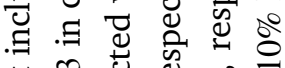

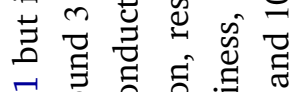

ᄀु 웅 वे

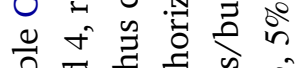

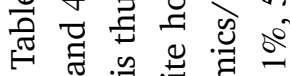

용 0

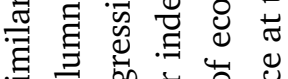

悬

․ㅗㄱ

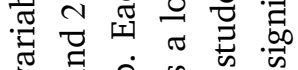

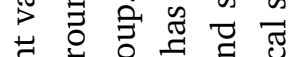

可 4 b

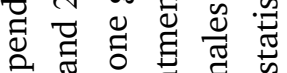

- 1 क क

๘

进罗专

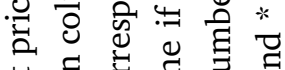

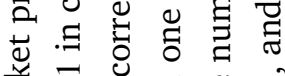

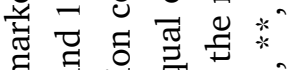

ह

ष

घ

言芯

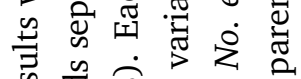

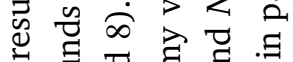

ప ప ప

윰

屯 ป है

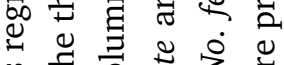

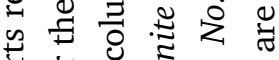

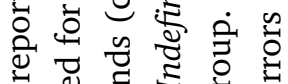

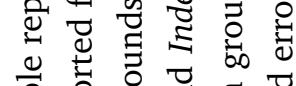

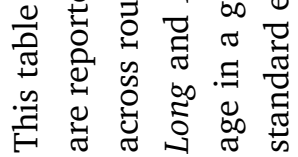




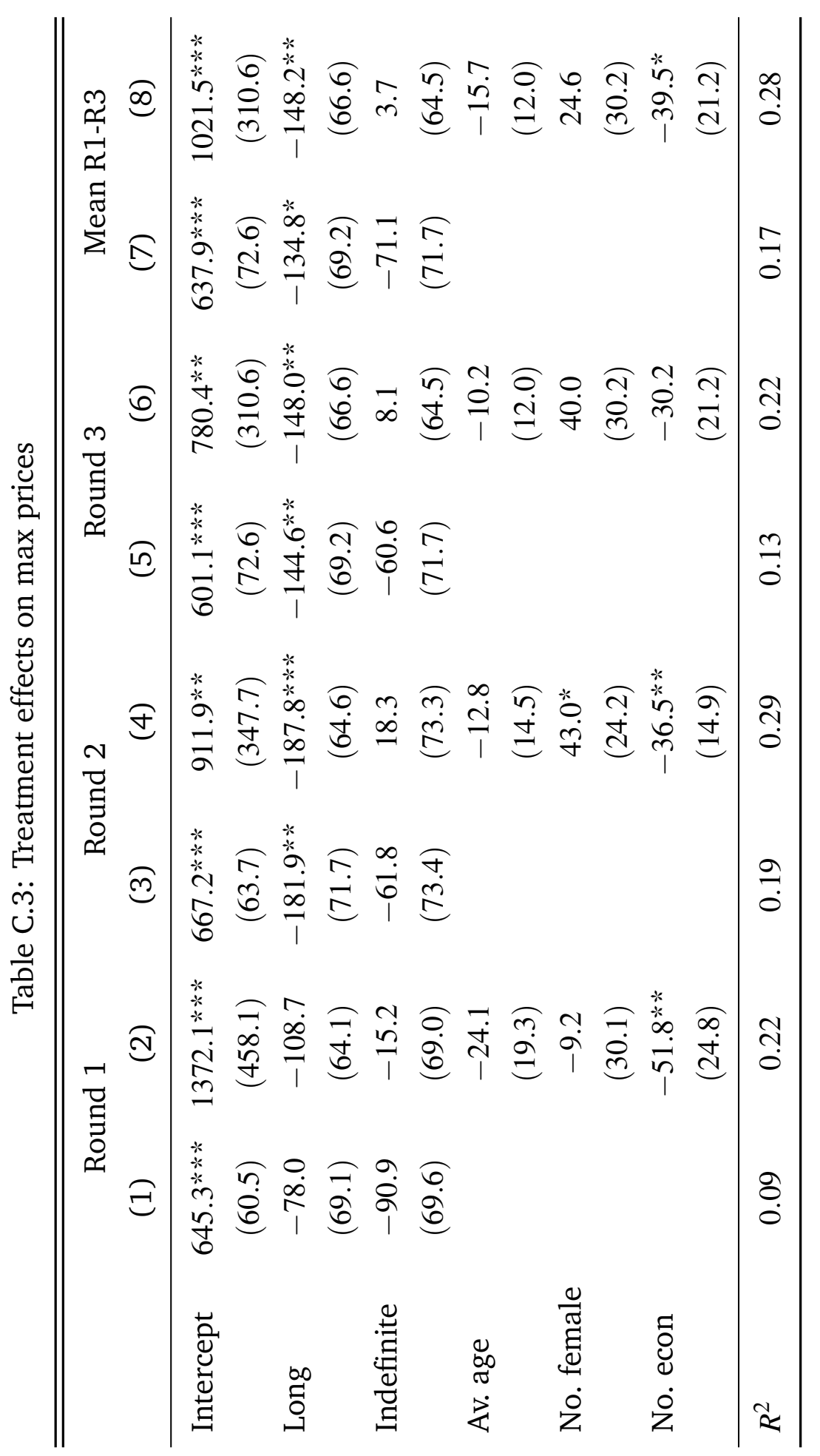

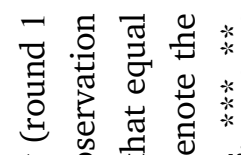

खे 䒕式 矛

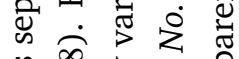
节范范 웜

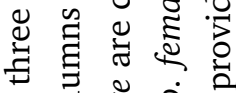
‡

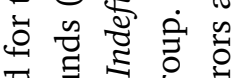
उ

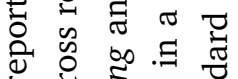
む कै 8 के

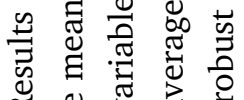
此㲾

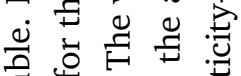
पू సี ส 苟 6 苞 㐘

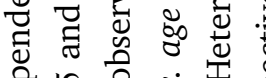

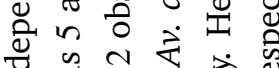
ป त

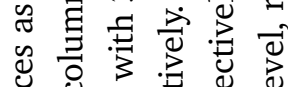

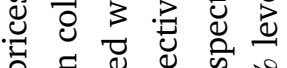

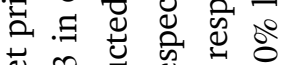

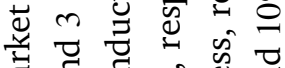
สี

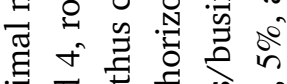
预 ⿷匚⿳丨コ丨 उ

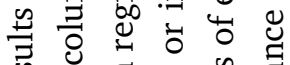
ญ

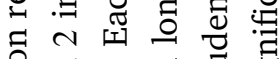

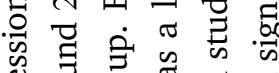

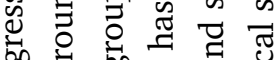
我

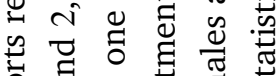

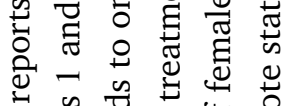

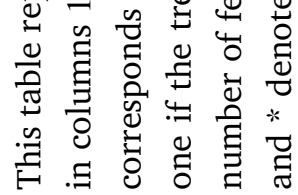




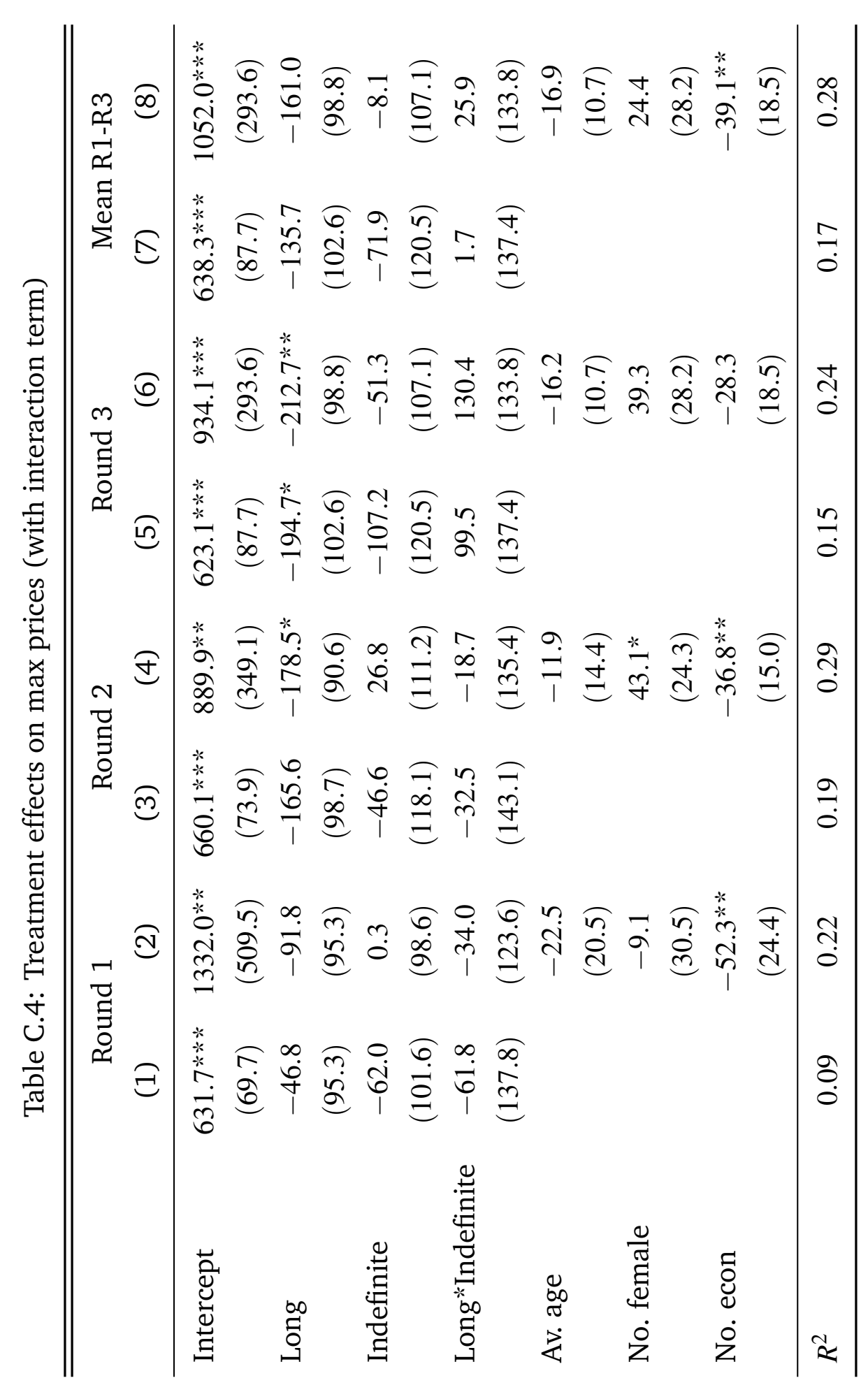

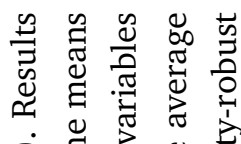

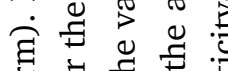
¿ .

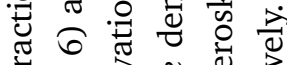

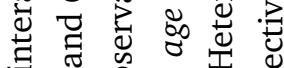

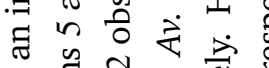

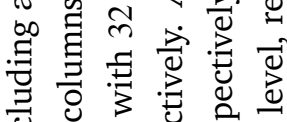

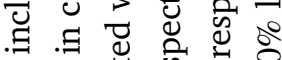

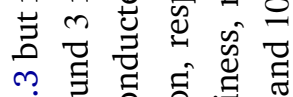

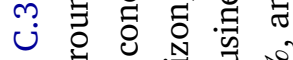

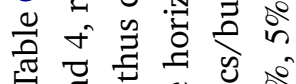
茪

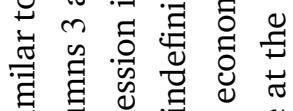
ن 光 귬

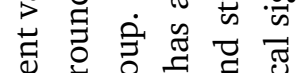
ते कू चे y

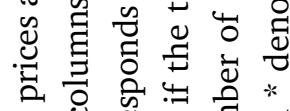

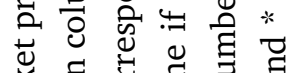

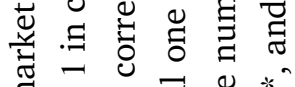
艼 ত

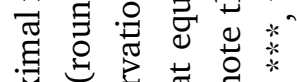

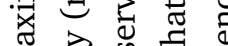
घ एँ

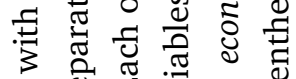
苟零 जै ปิ .

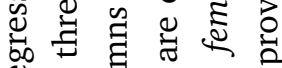
¿

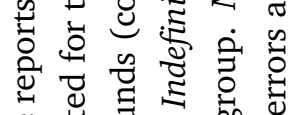
峁 ज्ञ

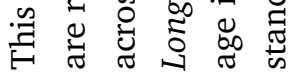




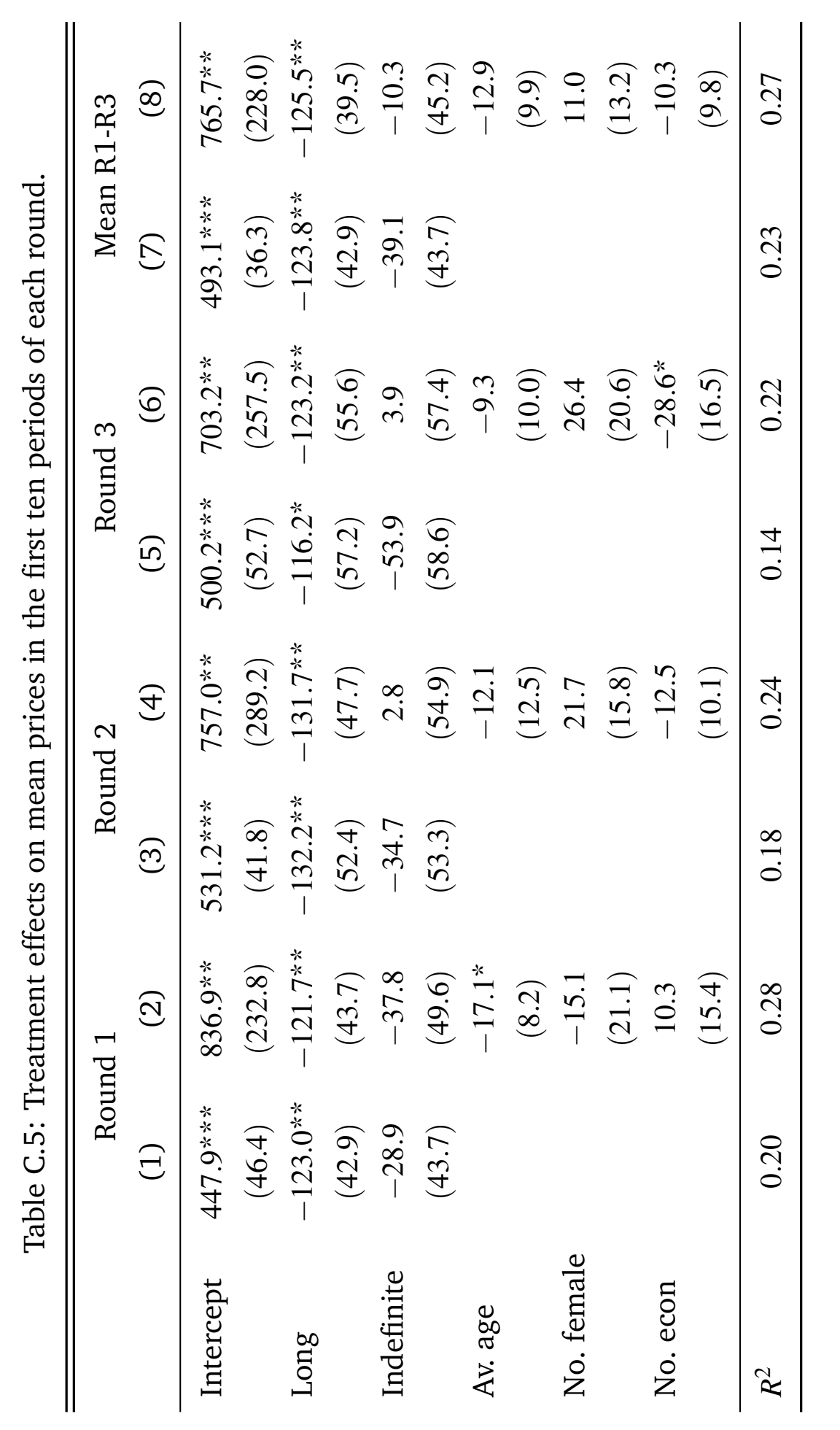

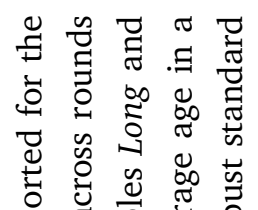
ญ む) 节至 ปั) ๑ ত

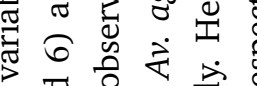
च 0 से 苞 向

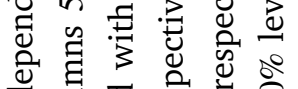
ণ ت

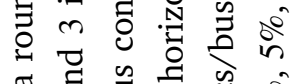

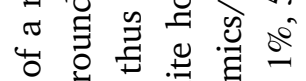

告

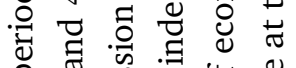

‡ స

站

离

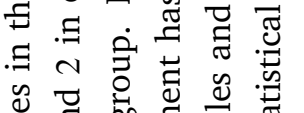

记

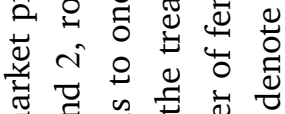

䒕 তี

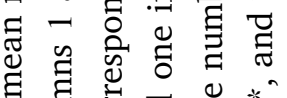

吉豆

了

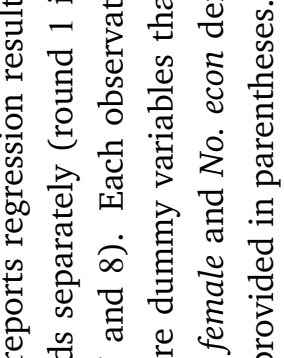

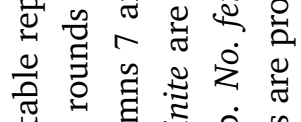
元 


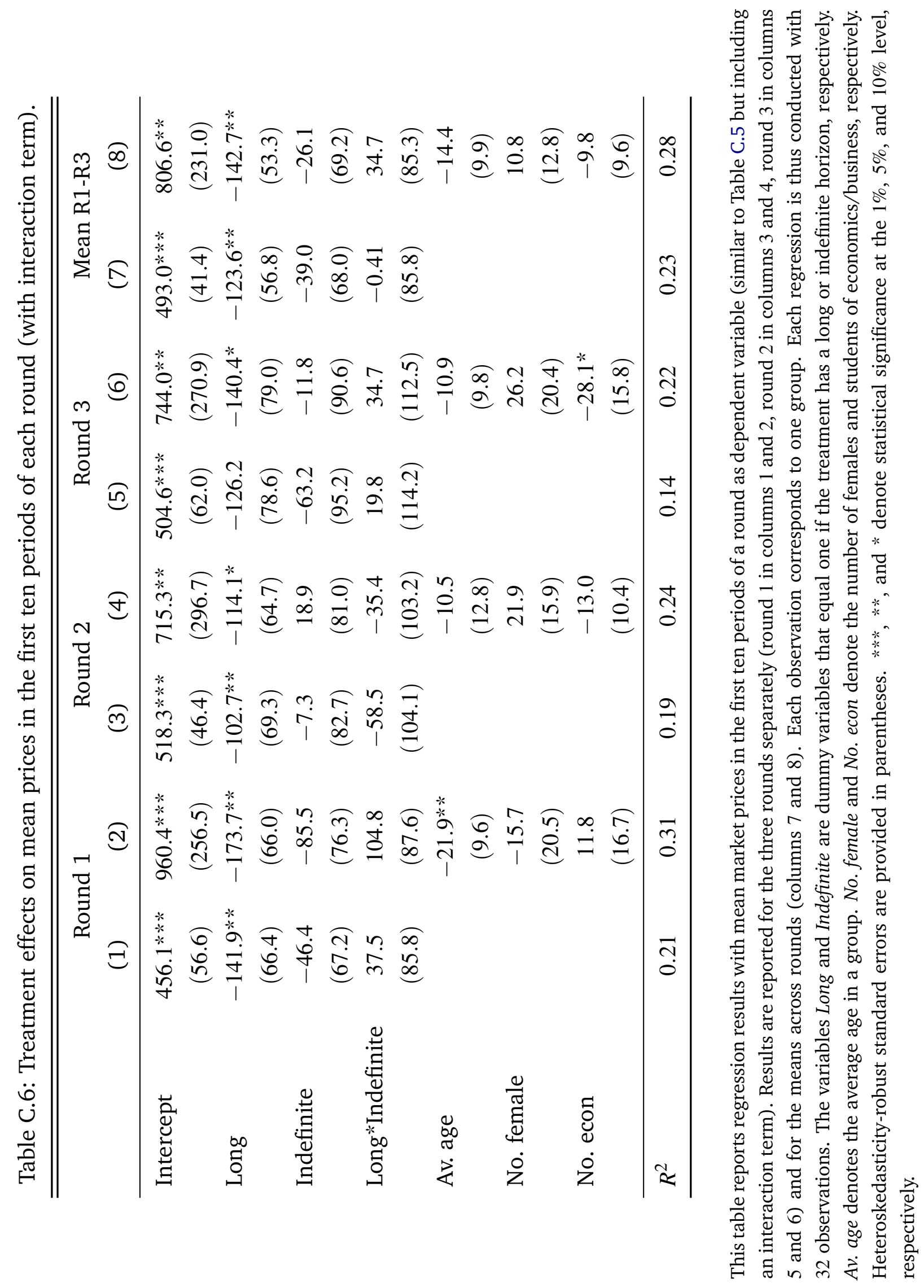




\section{C.2 Learning and Speeding Up of Bubbles}

Table C.7 contains the full regressions for the main learning variable. The dependent variable is mean prices in the first round minus mean prices in the third round (coefficient estimates of the treatment variables are shown in the main text in Table 2). Table C.8 contains the same regressions with the dependent variable maximal prices in the first round minus maximal prices in the third round.

Table C.7: Treatment effects on mean prices R1 minus R3 (learning)

\begin{tabular}{lcccc}
\hline \hline & & & & \\
& $(1)$ & $(2)$ & $(3)$ & $(4)$ \\
\hline Intercept & 13.9 & -14.0 & 488.5 & 383.8 \\
& $(72.8)$ & $(90.8)$ & $(319.9)$ & $(359.6)$ \\
Long & 35.3 & 98.9 & 28.4 & 72.6 \\
& $(57.2)$ & $(101.9)$ & $(60.7)$ & $(105.1)$ \\
Indefinite & 3.4 & 62.6 & -18.3 & 22.2 \\
& $(59.3)$ & $(97.7)$ & $(53.6)$ & $(93.2)$ \\
Long*Indefinite & & -126.3 & & -88.9 \\
& & $(112.7)$ & & $(118.8)$ \\
Av. age & & & -17.0 & -13.0 \\
& & & $(11.1)$ & $(11.9)$ \\
No. female & & & -38.5 & -38.0 \\
& & & $(38.0)$ & $(37.7)$ \\
No. econ & & & 9.1 & 7.8 \\
& & & $(24.6)$ & $(23.5)$ \\
\hline$R^{2}$ & 0.01 & 0.04 & 0.11 & 0.12 \\
\hline
\end{tabular}

This table reports regression results with the dependent variable mean prices in the first round minus mean prices in the second round. Each observation corresponds to one group. Each regression is thus conducted with 32 observations. The variables Long and Indefinite are dummy variables that equal one if the treatment has a long or indefinite horizon, respectively. Av. age denotes the average age in a group. No. female and No. econ denote the number of females and students of economics/business, respectively. Heteroskedasticityrobust standard errors are provided in parentheses. $* * *, * *$, and $*$ denote statistical significance at the $1 \%$, $5 \%$, and $10 \%$ level, respectively. 
Table C.8: Treatment effects on max prices R1 minus R3 (learning)

\begin{tabular}{lcccc}
\hline \hline & & & & \\
& $(1)$ & $(2)$ & $(3)$ & $(4)$ \\
\hline Intercept & 44.2 & 8.6 & 591.7 & 398.0 \\
& $(93.2)$ & $(115.4)$ & $(509.6)$ & $(569.3)$ \\
Long & 66.6 & 147.9 & 39.2 & 120.8 \\
& $(77.0)$ & $(129.2)$ & $(84.8)$ & $(136.9)$ \\
Indefinite & -30.3 & 45.3 & -23.3 & 51.6 \\
& $(78.9)$ & $(123.7)$ & $(63.8)$ & $(105.6)$ \\
Long*Indefinite & & -161.3 & & -164.5 \\
& & $(151.8)$ & & $(145.9)$ \\
Av. age & & & -13.8 & -6.3 \\
& & & $(18.3)$ & $(19.4)$ \\
No. female & & & -49.2 & -48.4 \\
\multirow{2}{*}{ No. econ } & & & $(47.5)$ & $(46.7)$ \\
& & & -21.6 & -24.0 \\
& & & $(37.5)$ & $(35.9)$ \\
\hline$R^{2}$ & 0.02 & 0.05 & 0.10 & 0.13 \\
\hline
\end{tabular}

This table reports regression results with the dependent variable maximal prices in the first round minus maximal prices in the second round. Each observation corresponds to one group. Each regression is thus conducted with 32 observations. The variables Long and Indefinite are dummy variables that equal one if the treatment has a long or indefinite horizon, respectively. Av. age denotes the average age in a group. No. female and No. econ denote the number of females and students of economics/business, respectively. Heteroskedasticity-robust standard errors are provided in parentheses. $* * *, * *$, and $*$ denote statistical significance at the $1 \%, 5 \%$, and $10 \%$ level, respectively. 
Table C.9 contains the full regression results on the speeding up of bubbles, with as dependent variable the difference between mean prices computed in the first half of the periods as a fraction of the mean price computed on all periods (R3 minus R1; coefficients of treatment variables are shown in the main text in Table 2).

Table C.9: Difference between mean prices computed in the first half of the periods as a fraction of the mean price computed on all periods, R3 minus R1 (speeding up of bubbles).

\begin{tabular}{lcccc}
\hline \hline \multirow{2}{*}{ Intercept } & & & & \\
& $0.22^{* *}$ & $0.15^{* *}$ & $1.25^{* *}$ & 0.87 \\
Long & $(0.06)$ & $(0.05)$ & $(0.49)$ & $(0.54)$ \\
& 0.02 & $0.19^{*}$ & -0.02 & 0.14 \\
Indefinite & $(0.09)$ & $(0.09)$ & $(0.08)$ & $(0.09)$ \\
& -0.03 & 0.13 & 0.06 & 0.21 \\
Long*Indefinite & $(0.09)$ & $(0.13)$ & $(0.09)$ & $(0.13)$ \\
& & $-0.34^{*}$ & & $-0.31^{*}$ \\
Av. age & & $(0.17)$ & & $(0.16)$ \\
& & & $-0.04^{*}$ & -0.02 \\
No. female & & & $-0.02)$ & $(0.02)$ \\
& & & $(0.03)$ & -0.01 \\
No. econ & & & $-0.05^{*}$ & $-0.06^{*}$ \\
& & & $(0.03)$ & $(0.03)$ \\
\hline$R^{2}$ & 0.00 & 0.11 & 0.13 & 0.21 \\
\hline
\end{tabular}

This table reports regression results with the dependent variable 'difference between first and third round of the mean price in the first half of a round divided by the mean price in the entire round'. Each observation corresponds to one group. Each regression is thus conducted with 32 observations. The variables Long and Indefinite are dummy variables that equal one if the treatment has a long or indefinite horizon, respectively. Av. age denotes the average age in a group. No. female and No. econ denote the number of females and students of economics/business, respectively. Heteroskedasticity-robust standard errors are provided in parentheses. ***, **, and * denote statistical significance at the $1 \%, 5 \%$, and $10 \%$ level, respectively. 